March 16, 2004

\title{
Do tender offers create value? New methods and evidence
}

\author{
Sanjai Bhagat ${ }^{a}$, Ming Dong ${ }^{b}$, David Hirshleifer $^{c, *}$, Robert Noah $^{d}$ \\ ${ }^{a}$ Leeds School of Business, University of Colorado, Boulder, CO 80309-0419, USA \\ ${ }^{b}$ Schulich School of Business, York University, Toronto, Ont. M3J 1P3, Canada \\ ${ }^{c}$ Fisher College of Business, Ohio State University, Columbus, OH 43210-1144, USA \\ ${ }^{d}$ Cambridge Finance Partners, LLC, Cambridge, MA 02139, USA
}

We develop the Probability Scaling Method, which rescales short-window announcement period returns; and the Intervention Method, which uses returns associated with intervening events, to estimate value improvements from tender offers. These methods address biases in conventional techniques, which measure only a fraction of the total tender offer gain; and which include revelation about bidder stand-alone value. Perceived value improvements are much larger than traditional methods indicate, so that we cannot reject the hypothesis that bidders on average pay fair prices for targets. Furthermore, our new methods affect inferences about economic forces in the takeover market. We identify several effects (higher combined bidder-target stock returns for hostile offers, lower for equity offers, and lower for diversifying offers) that reflect differences in revelation about stand-alone value, not gains from combination.

JEL classification: G12; G34

Keywords: Tender offers; Value improvements; Truncation dilemma; Revelation bias; Agency problems

We thank Daniel Asquith, Randolph Beatty, Bernard Black, James Brickley, Henry Cao, Nick Crew, Wayne Ferson, Ruth Friedman, Stuart Gilson, David Heike, Steve Kaplan, Dick Kazarian, Seongyeon Lim, Andrew Lo, Uri Lowenstein, Gershon Mandelker, Wayne Marr, Timothy Opler, Jeff Pontiff, Ed Rice, Matt Richardson, Scott Richardson, Richard Roll, Anil Shivdasani, René Stulz, Sheridan Titman, Garry Twite, Ivo Welch, J. Fred Weston, Jerold Zimmerman, and seminar participants at the University of Arizona, University of British Columbia, University of Chicago, Clemson University, University of Michigan, University of Missouri, University of Rochester, Southern Methodist University, University of Southern California, Tulane University, University of Washington at Seattle, Yale University, York University, the U. S. Federal Trade Commission, the Securities and Exchange Commission, the American Finance Association Meetings, the Econometric Society Meetings, the Northern Finance Association meetings, and the Western Finance Association Meetings for valuable comments.

*Corresponding author. (614) 292-5174; fax: (614) 292-2418; hirshleifer_2@cob.osu.edu 


\section{Do tender offers create value? New methods and evidence}

We develop the Probability Scaling Method, which rescales short-window announcement period returns; and the Intervention Method, which uses returns associated with intervening events, to estimate value improvements from tender offers. These methods address biases in conventional techniques, which measure only a fraction of the total tender offer gain; and which include revelation about bidder stand-alone value. Perceived value improvements are much larger than traditional methods indicate; we cannot reject the hypothesis that bidders on average pay fair prices for targets. Furthermore, our new methods affect inferences about economic forces in the takeover market. We find several effects (higher combined biddertarget stock returns for hostile offers, lower for equity offers, and lower for diversifying offers) that reflect differences in revelation about stand-alone value, not gains from combination. 


\section{Introduction}

Attempts to estimate the value effects of takeovers face two important challenges. We call the first challenge the truncation dilemma. Since not all takeover bids succeed, a short event window that extends only a few days past the bid announcement date estimates only a fraction of the value effects of successful takeover. ${ }^{1}$ A long window that extends through successful completion of the transaction can capture the full effect on value. However, this comes at the cost of introducing much greater noise and return benchmark errors.

The second challenge, which we call the revelation bias, is that the bidder's return on the announcement date reflects not just news about the value to be derived from combination, but news about the stand-alone value of the bidder. For example, firms sometimes deliberately time the announcement of takeover bids to be simultaneous with unrelated announcements. ${ }^{2}$ More importantly, as discussed further in Subsection 2.1, the very fact that a firm makes a bid will usually convey information to investors about the bidder's stand-alone value.

To address these issues, we estimate the stock market's perception of value improvements from tender offers using both conventional abnormal stock returns at the time of the initial bid, and two new approaches. In our comprehensive 1962-2001 sample, all approaches imply substantial value improvements. Furthermore, the new methods imply estimates of shareholder value improvement that are much larger than those implied by traditional methods.

The first new method, the Probability Scaling Method (PSM), uses returns associated with the announcement of the initial bid. Like most past studies, the return cumulation window extends only a short time after the event. PSM then adjusts returns derived from this short window upward to reflect the probability that the offer will fail. It addresses the truncation dilemma by exploiting ex post information about frequency of success to capture the missing slice of the gains from takeover.

The second new approach, which we call the Intervention Method (IM), extracts information about value improvement from the stock returns associated with intervening events such as the announcement of a competing bid. Like PSM, IM addresses the truncation

\footnotetext{
${ }^{1}$ More precisely, it estimates a probability-weighted mixture of the gain from takeover by the first bidder and by a possible later bidder that may appear, where the total probability of acquisition is less than one.

${ }^{2}$ The WSJ reported: 'It's Wall Street's version of 'Wag the Dog.' Over the past week, both Mattel and Coca-Cola have announced acquisitions on the same day they also issued warnings about disappointing earnings. ... No one is suggesting that either company unveiled its acquisition solely to divert attention from its problems... But it is also clear that the acquisitions, like the [Iraq] bombings, helped shift attention away from other less favorable developments." The article gives other examples as well (WSJ, "Heard on the Street', 12/18/98, p. C1).
} 
dilemma through appropriate scaling of returns. At the same time, IM also addresses the revelation bias, which taints estimates of the gain to takeover in past market and accounting studies. A disadvantage of IM, however, is that it relies heavily on the subsample in which an intervening event occurs such as arrival of a competing bid.

The development of the probability scaling and the intervention methods, and the use of these methods to estimate underlying value improvements from tender offers, are the main contributions of this paper. We find that value improvements from tender offers are on average perceived by investors to be positive and substantially larger than estimates from previous studies. Conventional combined abnormal returns and the PSM estimate are positive in $71 \%$ of the sample (694 out of 976 transactions). In the competing bid subsample, the IM estimate is positive in over $93 \%$ of the sample (132 out of 141 competing-bid transactions). In both the general and the competing bid samples, the conclusion that takeover improvements are on average positive and substantial is robust with respect to several alternative model specifications and plausible variations in the estimated parameters, and holds in all subperiods. Using traditional event-period weighted-average returns as in Bradley, Desai and Kim (1988), hereafter BDK-88, yields a combined mean (median) improvement of $5.3 \%(3.7 \%)$ of combined bidder-target value. PSM estimated value improvements tend to be considerably larger - a mean of $7.3 \%$ (median $4.6 \%$ ) of combined value.

Value improvements are particularly large in the competing bid subsample. The average estimated $I M$ improvement in this sample is approximately $13.1 \%$ (12.4\%) of combined bidder/target value. Using PSM, the average improvement is $14.7 \%$ (9.7\%). Again these numbers are greater than the estimates of $9.0 \%$ (7.6\%) using conventional combined abnormal returns in the competing bid subsample. ${ }^{3}$

Using a traditional announcement period estimation method, bidders on average pay a significantly higher premium for the shares they purchase in the offer than the improvement in target share value under bidder control. In contrast, using both of the new methods developed here, we cannot reject the null hypothesis that the payment is on average fair.

Furthermore, we find that traditional methods lead to incorrect inferences about economic forces in the takeover market. We find that friendly offers, equity offers, and diversifying offers are associated with lower combined bidder-target stock returns. A conventional interpretation would be that the gains from combination are smaller for firms involved with

\footnotetext{
${ }^{3}$ Another reason that the traditional method can understate the true value improvement is that stock prices of acquirers may already reflect an expectation that acquirers will undertake new projects including mergers. For example, an acquisition may be part of a merger program and market reaction to a takeover bid may only capture the surprise relative to expectations (Schipper and Thompson, 1983). However, our probability scaling method demonstrates that the portion of the value improvement that investors learn about at takeover announcement date is substantially underestimated by traditional methods.
} 
these types of transactions. However, our new methods indicate that these effects reflect differences in revelation about stand-alone value, not differences in the gains from combination.

For example, cash offers on average are associated with higher bidder, target and combined abnormal returns than equity or mixed-payment offers. In contrast, based on the intervention method, cash offers do not create higher value improvements than mixed or equity offers. These findings indicate that the apparent superiority of cash offers in creating shareholder value is an illusory consequence of a more negative revelation effect for equity or mixed offers than for cash offers. This suggests that there is adverse selection in the use of equity rather than cash as a medium of exchange in takeovers. Also, our finding does not support the hypothesis that the use of cash reveals to investors a general propensity for managers to waste cash on bad projects.

Similarly, we find that the revelation bias is more favorable for hostile than for friendly offers. On average the market revises upward (downward) its stand-alone valuation of bidders that make hostile (friendly) bids. ${ }^{4}$ This is consistent with investors interpreting hostile bids as indicating that the bidder has strong cash flow prospects as a stand-alone entity, and interpreting friendly bids as indicating severe bidder agency problems.

Furthermore, conventional combined returns, PSM value improvements, and bidder returns tend to be lower in diversifying acquisitions. The finding of lower bidder returns indicates that the conclusions of Morck, Shleifer and Vishny (1990) continue to apply in a dataset that includes the turn of the millennium. In sharp contrast, IM estimates of value improvements are similar across these categories. The relative superiority of same-industry acquisitions with PSM (which does not filter out revelation effects) compared to IM (which does) indicates that same-industry acquisitions are associated with more favorable revelation than cross-industry acquisitions.

This finding suggests that investors perceive diversifying acquisitions as indicating poor investment opportunities within the bidder's own industry, or else that management is prone to agency problems. It further suggests that it is updating about the quality of the bidder's investment opportunities or management, rather than about the advantages of the combination, that leads to lower returns in diversifying transactions.

We also identify some factors that do affect the gains from combination, not just revelation about stand-alone value. For example, using all three approaches, acquisition of a smaller target by a large bidder on average creates a smaller value improvement, measured as

\footnotetext{
${ }^{4}$ The phrase 'stand-alone' is used here to mean 'not combined with the current target.' It does not preclude the possibility that the market perceives bidder value as potentially coming from combination with a different target.
} 
a fraction of combined value, than combinations of similar-sized firms. But measured relative to the value of the target, the mean estimated improvement is larger for such transactions. These findings are consistent with the importance of both synergies and target-specific improvements such as removal of bad management. Although the business press has raised concerns about combinations of similarly-sized firms, these two results do not give any clear indication that bidder/target parity in tender offers is a bad thing.

Furthermore, bidder announcement period returns and total value improvements are negatively related to bidder Tobin's $Q$. This result is quite different from the evidence from earlier samples of Lang, Stulz, and Walkling (1989) and Servaes (1991), who found that returns to bidders and targets are higher when high $Q$ bidders acquire low $Q$ targets. Our finding is consistent with the finding of Dong et al (2003) that bidders with low book/market ratios (which are negatively correlated with $Q$ ) tend to have more negative announcement period returns. Target announcement period returns are negatively related to target $Q$, consistent with previous literature.

In summary, the new methods offered here affect several conclusions about tender offers. In addition to the quantitative conclusion that tender offers produce greater gains than previously estimated, out approach offers conclusions that contrast with those of conventional methods about how means of payment is related to value improvements; what offer hostility indicates about bidder agency problems; whether diversifying acquisitions harm value, or just reveal adverse information about stand-alone firm prospects; and whether bidders pay too much. These differences highlight the importance of our new methods for drawing qualitative as well as quantitative inferences about tender offers.

The next section develops an empirical measure of value improvements. Section 3 describes the tender offer data. Value improvement estimates of tender offers are presented in Section 4. The final section concludes.

\section{Measurement of takeover value improvement}

\subsection{Motivation}

A large previous literature uses stock return data to estimate shareholder gains from takeovers, usually in the form of separate estimates of bidder or target gains. Such estimates reflect the gain from combination, and also depend on how this surplus is divided between bidder and target. ${ }^{5}$ To estimate the total gains from combination, BDK-88, examined a market-value-

\footnotetext{
${ }^{5}$ Numerous studies find significant and large positive average abnormal returns for target shareholders. Jensen and Ruback (1983) and Jarrell, Brickley, and Netter (1988) review this evidence; more recently, see Schwert (1996). In contrast, abnormal returns for takeover bidders tends to average fairly close to zero.
} 
weighted average of abnormal returns of paired bidders and targets in successful takeovers. They examined an event window that extends to 5 days after the initial announcement of the ultimately successful bid. Since there remains substantial uncertainty about ultimate success of the bid at this point, this therefore provides an estimate of only a fraction of the market's assessment of the total value gains from takeover. BDK-88 find that the marketvalue-weighted average of bidder and target abnormal returns for successful takeovers during the period 1962-1984 is positive and stable over this period, with an average increase of $7.4 \%$ of combined bidder/target market value. This is their estimate of magnitude of synergistic gains from takeover.

Ideally, as recognized by BDK-88, an event window that extends from (well before) the initial announcement through final successful resolution should be used to capture the full value effects of takeover. Takeover contests often take as long as 3-6 months between first announcement and final resolution. Such long periods introduce a great deal of noise arising from random price movements and errors owing to misestimation of benchmark returns. Long periods also raise issues of the correct way to compound. ${ }^{6}$ Empirically, Andrade, Mitchell and Stafford (2001, p. 110) report a slightly higher average return for the [-20, close] announcement window than using a $[-1,+1]$ window. However, the return estimate becomes noisy as the window extends to the resolution of the takeover bid (with an average window length of 142 days), and this estimate cannot be reliably distinguished from zero.

A short post-announcement window minimizes such noise and benchmark error, because a significant security-specific news arrives on a single day, whereas (if only factor risk is priced) the risk premium for a single day is negligible. However, a short window estimates only a fraction of the full value effect of a successful transaction. ${ }^{7}$ This is the truncation dilemma.

Several authors have emphasized a second problem for estimating the value effects of takeovers (Bradley, Desai and Kim, 1983; Jensen and Ruback, 1983; Roll, 1986; Jovanovic and Braguinsky, 2002). This is that the announcement of an offer and its form reveals bidder information not just about the gain from combination, but about the bidder's stand-alone

\footnotetext{
${ }^{6}$ The market model is biased to the extent that bids occur after the bidder has experienced abnormally good times (Franks, Harris, and Titman, 1991). Barber and Lyon (1997), and Kothari and Warner (1997) study problems of misspecification associated with the use of long-horizon returns, and the effectiveness of alternative benchmarks.

${ }^{7} \mathrm{~A}$ familiar problem, which is not our primary focus, is that a short pre-event window omits the effects of probability revisions associated with information leaking out prior to the official public announcement date. Furthermore, we estimate market perceptions of value improvements; these perceptions are sometimes incorrect; see, e.g., the model of Shleifer and Vishny (2003), tests of market misvaluation based upon postacquisition long-run stock returns (Loughran and Vijh, 1997; Rau and Vermaelen, 1998; Mitchell and Stafford, 2000; Andrade, Mitchell and Stafford, 2001; Moeller, Schlingemann and Stulz, 2003a, 2003b) and through contemporaneous measures (Dong et al, 2003).
} 
value. As a result, takeover-related returns do not provide a pure measure of the gain to shareholders from takeover.

For example, the occurrence of a bid may convey the good news that a bidder expects to have high cash flows, the bad news that the bidder has poor internal investment opportunities $^{8}$, or the bad news that the bidder's management has empire-building propensities. Similarly, the premium offered can convey good or bad news about the bidder's stand-alone prospects. Also, the 'lemons problem' with equity issuance implies that the use of equity as a means of payment will convey bad news about the bidder's assets in place, and that the use of cash will convey good news. ${ }^{9}$ In contrast, free cash flow/agency problems suggest that the announcement of a cash bid may reveal that the firm has excess cash flow relative to profitable internal investment needs and that management is likely to waste that cash on poor investments.

It follows that the market-value-weighted average of bidder and target equity returns provides a biased estimate of the long-run total equityholder gain from takeover. We term the error in these estimates arising from managers' information about stand-alone value the revelation bias. ${ }^{10,11}$

This paper describes empirically abnormal stock returns associated with announcement of tender offers in a sample that extends to the turn of the millenium, ${ }^{12}$ and offers new

\footnotetext{
${ }^{8}$ See, e.g., Jovanovic and Braguinsky (2002); the WSJ, 12/18/98, p. C1, Heard on the Street describes the viewpoint of analysts that "Executives who see slowing growth often look outside their companies for acquisition opportunities."

${ }^{9}$ See Myers and Majluf (1984), Hansen (1987), Fishman (1989), and Eckbo, Giammarino and Heinkel, (1990); and the evidence of Travlos (1987) and Franks, Harris and Titman (1991).

${ }^{10}$ Revelation effects should be distinguished from signalling, the special case in which the bidder modifies his acquisition decision for the purpose of influencing short-term market perceptions. In general bidder actions will convey information to the market, regardless of whether the bidder seeks to alter market beliefs. Our approach can accommodate, but does not require, that signalling motives be an important consideration in the decision of whether to make an acquisition. Even if signalling motives are not relevant, the decision to make an offer will in general reveal information possessed by the bidder, in the ways discussed in the above paragraph.

${ }^{11}$ An alternative to stock market evidence is to examine accounting or other performance measures following completed transactions. Several studies have drawn very different conclusions about whether takeovers on average increase or decrease combined fundamental value (e.g., Mueller, 1985; Healy, Palepu, and Ruback, 1992; Kaplan and Weisbach, 1991; Bhagat, Shleifer, and Vishny, 1990.) Although such studies are quite informative, they usually do not quantify the total discounted value effect of takeovers. More importantly, these studies are potentially subject to problems of noise, benchmark error, and revelation bias analogous to those of stock market-based studies. For example, in regard to revelation bias, an offer may be associated with future accounting improvements which would have occurred even without a takeover.

${ }^{12}$ Andrade, Mitchell and Stafford (2001) and Moeller, Schlingemann and Stulz (2003a, 2003b) have described several aspects of the returns to takeovers including recent years. Andrade, Mitchell and Stafford (2001) draw a similar overall conclusion to ours, that takeovers have on average been perceived as value increasing. Moeller, Schlingemann and Stulz (2003a, 2003b) also find positive mean returns, but emphasize the negative dollar returns of large bidders during the 1998-2001 period.
} 
methods of estimating value improvements from takeover which address the truncation dilemma and the revelation bias in stock market studies. By controlling for these biases, our new methods imply much larger value effects than traditional techniques suggest, and imply different conclusions about the sources of takeover value improvements. These methods may be useful in other contexts as well for estimating the full value effects of corporate events, and for disentangling revelation effects from value effects of discretionary corporate actions.

Both new approaches address the truncation dilemma. Suppose, for example, that the event window is truncated 5 days after announcement. Then the market price at the endpoint still reflects substantial uncertainty on the part of investors about ultimate success of the offer or of any followup offer. The problem the financial economist faces is to infer the total value improvement effect from this fragment of it, much as an anthropologist infers the height of a hominid based on a fossilized leg bone.

The probability scaling method (PSM) adjusts returns for the possibility that the transaction is not completed. Ex post data is used to estimate the probability, given that a bid has taken place, that the bidder ultimately succeeds in acquiring the target; and the probability that some other bidder ultimately takes over the target. Based on these probabilities, the announcement period returns of bidder and target are magnified to measure the total perceived value effect of a completed transaction.

The intervention method addresses both the revelation bias and the truncation dilemma, by focusing on the returns at the time of a different event, the arrival of a competing bid. Because the arrival of a second bidder has a large effect on the probability of the initial bidder's success, the abnormal return observed for the initial bidder at this event implicitly reflects the size of the potential takeover value improvement. ${ }^{13}$ Furthermore, this event does not occur at the discretion of the initial bidder; it is an external intervention. This is crucial, because as such the arrival of a competing bid reveals little or nothing about the stand-alone value of the initial bidder. The intervention method calculates the value improvement implicit in the observed initial bidder return when a competing bid intervenes.

There are two key inputs to this calculation. The first is the amount by which the arrival of a competing bid reduces the probability that the first bidder succeeds in acquiring the target. The second input is the amount that the arrival of a competing bid increases the expected price that the first bidder will pay should it win the contest. ${ }^{14}$ Each of these quantities can be estimated from ex post data. Holding constant these parameters, the

\footnotetext{
${ }^{13}$ The term "value improvement" in this paper refers to joint bidder and target shareholder gains. Owing to possible wealth redistributions among other stakeholders such as employees and customers, this need not coincide with value to society as a whole.

${ }^{14} \mathrm{~A}$ third relevant input, the initial shareholding of the first bidder in the target, turns out to be relatively unimportant.
} 
abnormal return at the time of arrival of a competing bid is a decreasing function of the size of the takeover improvement - it is worse to lose a big improvement than a small one. Inverting this relationship, the size of the takeover improvement can be inferred from the observed abnormal return. A numerical illustration is provided in Appendix A.

Intuitively, the challenge for estimating value improvements is that two very different possibilities are consistent with a negative move in the first bidder's stock price upon the arrival of a competing bid. First, the acquisition may increase the first bidder's value, and arrival of the second bid conveys the bad news that this value is less likely to be realized by the first bidder. Second, the acquisition may decrease the first bidder's value, but the arrival of the second bidder conveys the bad news that the first bidder will on average pay a higher premium in the event that he succeeds. To disentangle these effects, we model the relation between these parameters and stock prices.

The methods that we use require some simplifying assumptions. Conventional methods make even stronger assumptions, though these assumptions are not explicit. For example, to interpret returns as value improvements using conventional weighted average event-date returns implicitly assumes that a short window can capture the whole value effect, and that there is no revelation bias. In this respect our approach has an important virtue relative to the conventional approach: it makes assumptions explcit. Doing so allows us to quantify explicitly the robustness of the conclusions to relaxing different simplifying assumptions.

Intervention method estimates depend on how competition affects the likelihood of offer success and bid premia. Several previous papers examine related issues. Betton and Eckbo (2000) estimate outcome probabilities in multiple bid tender offers as a function of offer premium, toehold, and the method of payment. An extensive theoretical literature considers the role of competing bidders in takeovers (Fishman 1988, 1989; Eckbo, Giammarino and Heinkel 1990; Ravid, and Spiegel 1999; and Bulow, Huang and Klemperer 1999).

Also, some previous papers have examined stock price reactions to events that interfere with takeover completion. These have focused either on testing for collusion and the effects of antitrust enforcement, or documenting the abnormal returns associated with the interfering event. Eckbo (1983) finds negative abnormal stock returns in merger bidders and targets on the announcement of an antitrust complaint. Bradley, Desai and Kim (1983) find a negative stock price reaction for a bidder upon announcement of a competing bid. Eckbo (1992) analyzes cross-sectional determinants of the market response to government anti-trust challenges of merger bids. He does not find that such policies deter collusive takeovers. Bradley, Desai and Kim (1988) find that targets receive a greater share of the value gains since the enactment of federal and state takeover legislation, and that offers with competing bids are associated with a more negative bidder abnormal return. Hietala, 
Kaplan and Robinson (2002) estimate takeover gains in a case study of competition in the 1994 acquisition of Paramount by Viacom. In contrast with these papers, our focus here in developing the intervention method is on extracting the size of value improvements from stock price reactions in a large sample of tender offers.

\subsection{Hypotheses}

The primary issue to be examined is whether takeovers on average increase the joint value of the bidder and target firms. According to Roll's (1986) Hubris Hypothesis, there is no value improvement from takeover; takeovers occur because of positive valuation errors by bidding managers. Agency problems can also lead bidding managers to pay more for targets than they are worth (e.g., "empire-building," and misuse of free cash). We therefore call the hypothesis of zero value improvement the Strong Agency/Hubris Hypothesis. If the Strong Agency/Hubris Hypothesis obtains, the expected value of the target to the bidder is the pretakeover market price of the target. If bidding costs are neglected, then the bidder makes negative profits equal in magnitude to the total premium paid for the purchased shares.

Since tender offers are frequently for less than $100 \%$ of outstanding shares, estimated bidder profits will depend on the assumptions made about the price paid for remaining shares given that control is obtained. For two reasons, the most natural assumption is that the same price is paid for holdouts as for the shares purchased in the tender offer. ${ }^{15}$ First, fairprice antitakeover amendments require paying at least this much to minority shareholders. Second, even if a successful bidder is able to expropriate minority shareholders, such dilution opportunities should be fully reflected in the initial bid price, so that holdout shareholders on average receive the same price as tendering shareholders (Grossman and Hart, 1980).

Let $\alpha$ refer to the fraction of the target's shares owned by the first bidder prior to the bid. Let $V_{0}^{T}$ be the nontakeover value of the target. Let $V^{C}$ be the combined post-takeover value of the first bidder and the target if the first bidder succeeds in acquiring the target, where this value is inclusive of any non-equity payments to shareholders as a result of the offer. Let the non-takeover value of the bidder be denoted $V_{0}^{B}$. Let $V^{I}$ be the value improvement from takeover. Then

$$
V^{I} \equiv V^{C}-V_{0}^{B}-V_{0}^{T}(1-\alpha) .
$$

The first term on the RHS is the total discounted value of cash flows going to bidder and target shareholders if the combination occurs. The last two terms subtract the total value

\footnotetext{
${ }^{15}$ Comment and Jarrell (1987) present evidence consistent with this assumption. More recently, it is not unusual for holdout investors to receive a package of securities with face value equal to the cash offer to initially-tendering investors.
} 
if there is no takeover. This is the sum of the values of the bidder and the target less the value of the bidder's stake in the target (which would otherwise be double-counted).

Letting a bar denote an expected value, the Strong/Agency Hubris Hypothesis asserts that the average value improvement is zero, i.e.,

$$
\bar{V}^{I}(\theta)=0
$$

where $\theta$ is the market's information set.

Some theoretical models predict that in the absence of dilution of minority shareholders, bidders will not on average profit on shares purchased in the offer (Grossman and Hart, 1980; Shleifer and Vishny, 1986; Hirshleifer and Titman, 1990). Even if a successful bidder loses money on these shares, he may still profit from the acquisition by increasing the value of the shares accumulated prior to the offer (Shleifer and Vishny, 1986). The prediction that the bidder profits on shares purchased in the tender offer is termed the Underpayment Hypothesis, as opposed to the Overpayment Hypothesis. The Overpayment (Underpayment) Hypothesis implies that the bid price on average exceeds (is less than) the value of the target shares to the bidder. Let $(1-\alpha) B$ be the total amount ultimately paid (in the form of either cash or securities) by a successful first bidder for shares purchased in or subsequent to the tender offer. For convenient comparison, this definition scales $B$ to be the notional price that would be paid if the bidder began with zero toehold and proceeded to purchase $100 \%$ of the firm. The amount paid by the bidder for the target (the 'price') includes the amount of cash paid to target shareholders and the market value of any security claims upon the combined firm given to target shareholders. The over/underpayment hypotheses can then be expressed as

$$
(1-\alpha)\left(\bar{B}-V_{0}^{T}\right) \gtrless \bar{V}^{I}
$$

where $\bar{B}$ denotes the expected value of the amount the initial bidder pays should he succeed. Dividing both sides by $V_{0}^{C} \equiv(1-\alpha) V_{0}^{T}+V_{0}^{B}$ gives

$$
(1-\alpha)\left(\frac{\bar{B}}{V_{0}^{T}}-1\right)\left(\frac{V_{0}^{T}}{V_{0}^{C}}\right) \gtrless \frac{\bar{V}^{I}}{V_{0}^{C}} .
$$

This condition describes whether the bid premium exceeds the value improvement, both measured relative to the initial combined bidder and target value.

\subsection{The probability scaling method of estimating value changes}

Let $\theta_{0}$ be all public information known prior to the first bid. Let $\theta_{1}$ be all public information known just after the first bid. Let $\theta_{2}$ refer to information known just prior to the arrival of a 
competing bid. Let $\theta_{3}$ contain in addition the information conveyed by the competing bid. Let dates $t=0,1,2,3$ refer to dates at which $\theta=\theta_{0}, \theta_{1}, \theta_{2}$ and $\theta_{3}$ respectively. Subscripts of $0,1,2$, and 3 will denote expectations formed conditional on these information sets.

Let $\bar{V}^{I}$ be the post-takeover improvement in combined value, as described in 1, conditional on the first bidder succeeding. Let $\phi_{t}$ denote the probability of success of the first bidder in acquiring the target given $\theta_{t}$ ( $\phi_{0}$ is the probability of a first bidder appearing and succeeding). Let $\bar{B}_{t}$ be the expected price paid by the first bidder should he win as assessed at date $t$, let $\phi_{t}^{L}$ be the probability that a first bid occurs and a later bidder $(L B)$ subsequently wins, let $\bar{B}_{t}^{L}$ be the expected price paid by such a winning bidder as foreseen at date $t$. A 1 subscript to variables indicate expected values formed after the arrival of the initial bid.

The conventional approach to estimating value improvements reflects the probabilities of acquisition by current or later bidders, $\phi_{0}$ and $\phi_{0}^{L}$, but does not estimate the probabilities. To provide meaning to this, some interpretation is needed. One possible interpretation that allows the conventional approach to be viewed as a value improvement is that the potential value improvements that would be brought about by the two potential bidders are equal, and that the probability that acquisition will be consummated by one or the other bidder is 1. The latter assumption is strong, and clearly counterfactual. In the Probability Scaling Method, we will relax this assumption.

Let $z$ be the sum of the stand-alone values of the first bidder and the target. As is implicit in the conventional approach, we assume that the average size of the improvement brought about by combination of a target with either the initial bidder or a later one is equal. Then the combined value of the first bidder and the target at date 0 is

$$
V_{0}^{C}=z+\phi^{0} \bar{V}^{I}
$$

where $\phi^{0} \equiv \phi_{0}+\phi_{0}^{L}$ is the market's assessment of the probability that the target is acquired by a potential bidder in the future. For simplicity, in this analysis we consider date 0 to be far enough in advance of the initial bid announcement that there is little market anticipation of the offer. Thus, the ex ante probabilities that a bidder appears and wins, $\phi_{0}$ and $\phi_{0}^{L}$ are close to zero. This implies that the prior expected target payoff is just the stand-alone value $V_{0}^{T}$, and the prior expected bidder payoff is just the stand-alone value $V_{0}^{B} \cdot{ }^{16}$

After the arrival of the initial bid, the market assigns a value $\phi_{1}+\phi_{1}^{L}$ to the probability that the target is acquired by a bidder. Therefore, the combined value of the first bidder

\footnotetext{
${ }^{16}$ As documented by Palepu (1986), takeovers are low probability events that are very hard to predict far in advance. More generally, the approach can be modified to allow for partial anticipation of offers, but given Palepu's evidence it is unlikely that doing so would affect the results substantially.
} 
and the target becomes

$$
V_{1}^{C}=z+\left(\phi_{1}+\phi_{1}^{L}\right) \bar{V}^{I} .
$$

It follows that the combined fractional market value improvement in the bidder and target is

$$
R_{1}^{C} \equiv \frac{V_{1}^{C}-V_{0}^{C}}{V_{0}^{C}}=\frac{\left(\phi_{1}+\phi_{1}^{L}\right) \bar{V}^{I}}{V_{0}^{C}},
$$

so normalizing the value improvement by combined value,

$$
\frac{\bar{V}^{I}}{V_{0}^{C}}=\frac{R_{1}^{C}}{\phi_{1}+\phi_{1}^{L}} .
$$

This formula provides a very simple implementation of the probability scaling method. We refer to the value improvement on the left hand side estimated from this PSM formula as the Probability Adjusted Improvement Ratio, or $I R^{P S M}$.

\subsection{The intervention method of estimating value changes}

We now describe the intervention method for estimating value improvements. The intervention method addresses the revelation bias as well as the truncation dilemma. However, it is based on a smaller subsample of returns (the competing bid subsample). The first step is to calculate the bidder's abnormal return between dates 1 and 3 in terms of the market's expectation of the value improvement $\bar{V}^{I}\left(\theta_{t}\right)$ at these dates. ${ }^{17}$ Then (using empirical estimates of unconditional and conditional probabilities of success and expected premia, abnormal returns and other parameters) we invert the relationship to infer $\bar{V}^{I}\left(\theta_{t}\right)$.

Consider the arrival of the competing bid at date 3. Let the market's assessment of the component of bidder's value not derived from the takeover be $y$. $y$ may not equal the preoffer value of the bidder as assessed by the market if the initial offer conveyed information about the bidder. We assume that the arrival of a competing bid is uninformative about the stand-alone value of the first bidder, so that $y$ is the same at dates 1,2 and 3 (before and after the arrival of the competing bid). Let $R_{3} \equiv\left(P_{3}-P_{1}\right) / P_{1}$ be the date 3 return associated with information $\theta_{3}$, where $P_{1}$ is the bidder's stock price just after the initial bid, and $P_{3}$ is the price based on $\theta_{3}$ after a competing bid arrives. So

$$
P_{3}=P_{1}\left(1+R_{3}\right) .
$$

Let $\bar{V}^{I}\left(\theta_{1}\right), \bar{V}^{I}\left(\theta_{3}\right), \bar{B}\left(\theta_{1}\right)$ and $\bar{B}\left(\theta_{3}\right)$ be abbreviated as $\bar{V}_{1}^{I}, \bar{V}_{3}^{I}, \bar{B}_{1}$ and $\bar{B}_{3}$ respectively. To relate $\bar{V}(\theta)$ to the observables $P_{3}$ and $P_{1}$, note that

$$
P_{1}=y+\bar{\pi}_{1}
$$

\footnotetext{
${ }^{17}$ For expositional simplicity, the model examines raw returns. For standard reasons, in implementing the model empirically abnormal returns are used.
} 


$$
P_{3}=y+\bar{\pi}_{3}
$$

where $\bar{\pi}_{t}$ is the bidder's expected profit from takeover conditional on information $\theta_{t}$,

$$
\begin{aligned}
& \bar{\pi}_{1}=\phi_{1}\left[\alpha \bar{V}_{1}^{I}+(1-\alpha)\left(\bar{V}_{1}^{I}+V_{0}^{T}-\bar{B}_{1}\right)\right] \\
& \bar{\pi}_{3}=\phi_{3}\left[\alpha \bar{V}_{3}^{I}+(1-\alpha)\left(\bar{V}_{3}^{I}+V_{0}^{T}-\bar{B}_{3}\right)\right] .
\end{aligned}
$$

We assume that the arrival of the competing bid at date 3 does not provide any information about the value improvement that the first bidder can effect through takeover. ${ }^{18}$ Hence, $\bar{V}_{3}^{I}=\bar{V}_{1}^{I}=\bar{V}^{I}$. The robustness of the results with respect to this assumption is analyzed in Section 4.5. ${ }^{19}$ The unobservable $y$ can be eliminated from (8), and the result combined with (9), giving

$$
\bar{V}^{I}=\frac{P_{3}-P_{1}}{\phi_{3}-\phi_{1}}-(1-\alpha) V_{0}^{T}+\frac{(1-\alpha)\left(\phi_{3} \bar{B}_{3}-\phi_{1} \bar{B}_{1}\right)}{\phi_{3}-\phi_{1}} .
$$

Dividing both sides of (10) by $V_{0}^{C}$ gives

$$
\frac{\bar{V}^{I}}{V_{0}^{C}}=\frac{R_{3}\left(P_{1} / V_{0}^{C}\right)}{\phi_{3}-\phi_{1}}+(1-\alpha)\left[\lambda\left(\frac{\bar{B}_{1}}{V_{0}^{T}}\right)+(1-\lambda)\left(\frac{\bar{B}_{3}}{V_{0}^{T}}\right)-1\right]\left(\frac{V_{0}^{T}}{V_{0}^{C}}\right),
$$

where

$$
\lambda \equiv \frac{\phi_{1}}{\phi_{1}-\phi_{3}} .
$$

We call the quantity on the left hand side of (11) the Intervention Method Improvement Ratio, or $I R^{I M}$. It is the market's estimate of the percentage improvement in the combined value of the bidder and target. In principle, every parameter in (11) can be given an $i$ superscript to denote the $i$ 'th takeover contest. However, we begin by developing the method in its most basic form by estimating certain parameters as sample means under the assumption that they are the same across contests. Under this approach, the terms $\bar{B}_{1} / V_{0}^{T}$ and $\bar{B}_{3} / V_{0}^{T}$ can be estimated as

$$
\frac{1}{n_{1}} \sum_{i=1}^{n_{1}}\left[B^{i} /\left(V_{0}^{T}\right)^{i}\right] \text { and } \frac{1}{n_{3}} \sum_{i=1}^{n_{3}}\left[B^{i} /\left(V_{0}^{T}\right)^{i}\right]
$$

\footnotetext{
${ }^{18}$ This would obtain under the Strong Agency/Hubris Hypotheses. More generally, the arrival of either an initial bid or competing bid could reveal information about target value. However, the evidence regarding the information conveyed by an initial bid is mixed. Bradley, Desai and Kim (1983) find that average cumulative abnormal returns of targets are approximately zero among targets of failed offers that are not later acquired. This suggests that there may be no permanent informational revaluation associated with the initial bid.

${ }^{19}$ This assumption is consistent with private information possessed by the second bidder. This could be information about a private component of its valuation of the target (e.g., a synergy unique to the second bidder). The second bidder can also possess information superior to that of investors about common value components (e.g., gains from remedying target management failure), so long as investors do not perceive the second bidder's information as adding to that of the first bidder.
} 
where $n_{1}$ is the number of initial offers, and $n_{3}$ the number of contests in which a competing bid occurs. Similarly, $\phi_{1}$ and $\phi_{3}$ can be estimated as the fraction of initial bids that succeed in the overall sample, and in the subsample in which a competing bid occurs, respectively. A more sophisticated approach is to estimate separate transaction-specific expected bid premia, by regression analysis; and probabilities of success using the logit model of Table 3; see Section 4.2 .

The model provides intuitively reasonable comparative statics. For example, assuming that the competing bid causes a drop in probability of success $\left(\phi_{3}<\phi_{1}\right)$, a more negative stock return on announcement of a competing bid indicates a larger value improvement. If the arrival of a competing bid implies that a much higher bid is needed to succeed, then for a given stock price reaction to the bid, the value improvement is smaller.

The quantities $R_{3}, P_{1} / V_{0}^{C}$, and $\alpha$ can be calculated directly and are specific to the takeover contest, to derive the value improvement ratio $I R^{I M}$. The intervention method makes no assumption whatsoever as to whether improvements are specific to changes in the bidder, the target, or involve joint synergies.

The Strong Agency/Hubris Hypothesis implies that this ratio is zero. The Overpayment and Underpayment Hypotheses are tested simply by comparing the average bid premium with the average estimated improvement given in (2).

The conventional approach is based on a variety of strong assumptions. For example, the conventional approach assumes that combined bidder/target returns reflect only the gains from the specific transaction, rather than the possibility of other acquisitions should the given transaction fall through. The conventional approach also assumes that revelation effects of the initial bid are zero. Furthermore, a conventional short-window return approach in effect implicitly assumes that, immediately after the initial offer, investors believe the offer will succeed with certainty.

Our implementation of the intervention method also makes several simplifying assumptions. Where we differ from the conventional approach is in making the relevant assumptions explicit. Doing so has the virtue of allowing assumptions to be evaluated critically, and suggesting how to test for robustness of the specification. The assumptions we apply are that the arrival of a competing bid does not cause investors to modify their assessment of the stand-alone value of the first bidder; that success of the initial bid is unrelated to the size of the value improvement; that a bidder whose offer fails is not able to locate and purchase another similar target at the same price; and that the unsuccessful initial bidder does not sell its toehold to a later bidder. Section 4.5 discusses and provides four modified versions of the model to evaluate quantitatively the effects of relaxing different assumptions. In brief, we find that the conclusion that the conclusion that value improvements are on average 
positive is highly robust.

\section{Data}

While the conventional method and the new methods developed here all apply to mergers as well as tender offers, in this paper we focus our empirical tests on a comprehensive sample of tender offers during 1962-2001. Our focus on tender offers is in the tradition of a large literature (e.g., Betton and Eckbo, 2000; Bhagat, Shleifer and Vishny, 1990; Lang, Stulz and Walkling, 1989; Bradley, Desai and Kim, 1988).

The initial tender offer data set was constructed from two sources. The first consists of 559 tender offers that were announced during the period October 1958 through December 1984. "It contains almost every tender offer made in the 1958-1984 period where at least one firm (the target or a bidder) was listed on the NYSE or AMEX...at some time between July 1962 and December 1984." ${ }^{20}$ This study investigates the wealth effects of a tender offer on both bidders and targets. We therefore restricted the sample to the 327 tender offers in which the bidder and target were both listed on the NYSE or AMEX. Additional dataavailability and data-consistency requirements reduced the sample size within the 1962-1984 sub-period to $292 .^{21}$

The second data source consists of all tender offers from 1985 through 2001, obtained from the Securities Data Company (SDC) Mergers and Acquisitions database. There were 778 tender offers with both the target and the acquirer publicly traded on the NYSE, AMEX or NASDAQ. After excluding 33 offers, the resulting number of tender offers from 1985 to 2001 in our dataset is $726 .^{22}$

To compile a history of the events that occur subsequent to a tender offer that might affect the probability of success of the bid, we manually searched the Wall Street Journal Index for the 292 target firms during 1962-1984, and used the online service Dow Jones Interactive to search the WSJ for information on the 726 target firms during 1985-2001, for a total of 1018. For these 1018 tender offers, we searched for the following informa-

\footnotetext{
${ }^{20}$ The quotation is from the write-up for the dataset compiled by Michael Bradley, Robert Comment, Anand Desai, Peter Dodd, and Richard Ruback. We thank these authors for providing us with their data.

${ }^{21} 12$ tender offers were announced prior to July 1962. The Daily CRSP tape does not contain returns prior to this date. Our verification of tender offer announcements and name changes led to some minor changes in the database.

${ }^{22}$ In 8 tender offers, the acquirer made a subsequent tender offer for the target and in these cases only the initial tender offers were included. We also excluded 11 tender offers where the bidder announced multiple takeovers at the same time. For both target and acquirer the SDC firm names and CUSIP numbers were manually matched with firms in the CRSP database. For 33 of the tender offers, CRSP data were not available either due to the required time period (e.g. a firm was delisted prior to the tender offer event) or due to failure to match the firm reported by SDC with a firm in the CRSP database.
} 
tion: litigation by the target firm or its shareholders; litigation by the bidding firm or its shareholders; a second bidder.

Table 1 records the frequency of the 1018 attempted tender offers during 1962-2001; see also Fig. 1. Using the criterion of success considered by BDK-83 - that the bidder acquires at least $15 \%$ of target shares in the tender offer - 690 or $68 \%$ of these offers were successful. 221 of these 1018 offers were considered hostile by the target management. A second bidder entered the contest in 147 of these 1018 tender offers. Target management litigated in 232 cases. Finally, 731 of these 1018 offers were all-cash offers.

Fig. 2 describes the percentage of successful and unsuccessful offers, the percentage of offers that had at least two bidders, the percentage offers considered hostile by target management, and the percentage of all cash offers during different periods.

\section{Returns to bidders and targets}

Table 2 summarizes the returns to bidder and target shareholders (where both companies were listed on NYSE, AMEX, or NASDAQ) during 1962-2001. Let the target and bidder returns be denoted $R^{T}$ and $R^{B}$ respectively, and let

$$
\omega \equiv \frac{(1-\alpha) V_{0}^{T}}{V_{0}^{C}} .
$$

Then CIBR, the combined initial bid return, is a weighted average of bidder and target abnormal returns,

$$
C I B R=\omega R^{T}+(1-\omega) R^{B}
$$

This is based on a conventional short-post-announcement-window returns (day -5 to +5 ). We define the dollar return for the target as its market value six days before the first bid multiplied by the target CAR; similarly for the bidder and combined dollar returns.

During this 40-year period, the average return to bidding shareholders has been a statistically insignificant $0.18 \% .{ }^{23}$ The bidder median dollar return is an economically insignificant -\$1.2 million. During this same 40-year period, target shareholders enjoyed a statistically and economically significant average return of $30.0 \%$ and median dollar return of $\$ 41.2$ million.

We describe returns to targets and bidders over various sub-periods in Table 2 and Figures 3-4. The first three sub-periods are as in BDK-88; July 1962 through June 1968 is the pre-Williams Act period, July 1968 through December 1980 is the post-Williams Act

\footnotetext{
${ }^{23}$ Statistical significance is measured using (a) the parametric Z-test as described by Dodd and Warner (1983), and (b) the non-parametric Fisher sign test.
} 
but pre-Reagan period. 1981-1984 was the final period considered by BDK-88. The fouryear sub-periods 1985-1988, 1989-1992, and 1993-1996 correspond roughly to presidential political cycles. Also, the 1981-1988 period was a highly active takeover market, aided perhaps by pro-merger policies of the Reagan administration. Some commentators have argued that the late-80s and early-90s, corresponding to our 1989-92 sub-period, were a time when deals were not economically attractive, but were being done for the sake of "doing the deal." The NASDAQ and several other broad stock indexes peaked in March 2000 , and many observers regard this period as close to the peak of the new economy stock bubble and a turning point of U.S. financial markets. We therefore divide the most recent portion of our sample periods between January 1997-March 2000, and April 2000-December 2001 subperiods.

Our results for bidder returns, target returns, and a value-weighted average for bidders and targets (the "combined" return), for the first three sub-periods (July 1962 - June 1968, July 1968 - December 1980, 1981-1984) are consistent with the findings of Bradley, Desai and Kim (1988). Table 2 indicates that during 1985-1988, the bidding shareholders earn a statistically insignificant mean return of $-.49 \%$ (median return of $-\$ 2.9$ million). During this same 1985-1988 period, the target shareholders received a statistically and economically significant return of $25.61 \%$ (median return of $\$ 37.3$ million).

As suggested earlier, the late-80s and early-90s (1989-1992) were not kind to bidders: mean return of $-1.78 \%$ (median dollar return of $-\$ 8.1$ million). Bidding shareholders generally fared better in the 1993-1996 sub-period: mean return of .98\% (median dollar return of $\$ 4.0$ million). The mean combined returns during 1993-1996 was 5.05\% (median dollar return of $\$ 55.5$ million). In the most recent sub-periods, bidders suffered wealth losses, although targets realized gains. The mean combined dollar returns were negative in the two post-1997 sub-periods (- $\$ 248.6$ million and $-\$ 25.3$ million, respectively), apparently due to big losses among bidders that were relatively large (Moeller, Schlingemann, and Stulz, 2003a, 2003b find even larger losses to large bidders in their mergers and tender offers sample during 1998-2001. They have relatively few tender offers in their large loss sample). The 1997-2000 mean dollar losses in our tender offer sample are of the same order of magnitude as the dollar gains in the 1993-96 period. 


\section{Estimates of value improvements}

\subsection{Parameter inputs for the probability scaling and intervention methods}

\section{Probability of first bidder success}

To use the probability scaling method, we need to estimate the probability that the first bidder is successful. Furthermore, since one of our objectives is to address the revelation bias, we need to identify an intervention that changes the probability that the first bidder succeeds, and which is not at the discretion of the first bidder. Litigation by the target, entry of a second bidder, and objection by a regulatory agency are examples of such exogenous events. Our focus is on the arrival of a competing bid, which is a major event for the initial bidder.

To estimate how the market's perception of probability of success is affected by the arrival of a competing bid, we need estimates of the market's perception of probability of success both prior to the competing bid (an 'unconditional' estimate), and subsequent to the bid (a 'conditional' estimate). We therefore estimate both a logit model that conditions only on information known to the market prior to the arrival of the competing bid, and a logit model which in addition conditions on the arrival of the bid.

Table 3 provides estimates of such models. The dependent variable equals one if the first bidder is successful and zero otherwise. Litigation $=1$ if the target files a lawsuit against the first bidder and zero otherwise. Competing bid $=1$ if a second bidder enters the bidding contest and zero otherwise. Hostile $=1$ if target management verbally opposes the first bid, and zero otherwise. $\alpha$ is the fraction of the target's shares held by the first bidder at the date of the initial offer. Effective premium is the premium offered by the first bidder using the target's price six days prior to the bid as the baseline, multiplied by the percentage of target shares sought by the bidder. Relative size is the bidder/target market value ratio. ${ }^{24}$

Model A does not condition on whether a competing bid has occurred; model B does. In measuring bidder returns we consider both a shorter and a longer window. The short window consists of the period one day before and the day of the first competing bid announcement for the target. The long window consists of the period one day after the first bid to the day of the first competing bid announcement for the target. For the short window, the market is likely by this time to have learned about the occurrence of litigation related to the initial bid if such litigation was going to occur. At the start of the longer window that begins

\footnotetext{
${ }^{24}$ Walkling (1985) and Schwert (2000) find some of the variables used here to be significant determinants of tender offer success.
} 
immediately after the arrival of the initial bid, the market is unlikely to have observed the occurrence of litigation even if it later occurs. Thus, for the short window Model A1 is appropriate, and for the longer window Model A2 is appropriate.

The results indicate that target management opposition, entry of a second bidder and the effective premium are determinants of bidder success (opposition and competition having negative effects), and, with somewhat lower significance, target litigation and relative size. ${ }^{25}$ Thus, the arrival of a competing bid does indeed have an important effect on offer success.

\section{Parameter inputs for the probability scaling method}

Estimating the probability scaling method improvement ratio $I R^{P S M}$ requires that returns be grossed up by the sum of the probabilities that the first bidder succeeds and that a later bid succeeds. This requires the following inputs:

- $\phi_{1}$ is the probability of success of the first bidder. In the full sample of 1018 cases the first bidder is successful in 690 instances. For both PSM and IM, we apply transactionspecific estimates using Logit model A2 in Table 3. $\phi_{1}$ can also be estimated globally as .6778 using a simple sample average.

- $\phi_{1}^{L}$ is the probability that a later bid succeeds in acquiring the target. We derive an estimate of this probability from Betton and Eckbo (2000) to be .1463.

\section{Parameter inputs for the intervention method}

The intervention method value improvement ratio $I R^{I M}$ is estimated based on equation (11). We consider bidder abnormal returns around the announcement of a competing bid. The abnormal returns are computed using the market model as the benchmark. ${ }^{26}$ During a two-day period consisting of the day of the publication of the news of the second bid in the WSJ and the day before, the mean abnormal return for the first bidder is $-.44 \%$, (median/min $/ \max$ are $-.42 \% /-11.71 \% / 12.57 \%$ ). The mean return for the period from one day after the publication of the news of the first bid in the WSJ to the day of the publication of the news of the second bid is $-3.58 \%$ (median $/ \min / \max$ are $-1.96 \% /-99.81 \% / 40.31 \%$ ).

The two-day mean average abnormal return on the date of arrival of a competing bid is close to zero. But as we have documented, the arrival of a competing bidder has powerful

\footnotetext{
${ }^{25}$ Target opposition is a matter of degree, see Schwert (2000); whereas the arrival of a competing offer is a discrete event. Thus, the latter seems a more appropriate subject for the intervention method.

${ }^{26}$ For the short return cumulation window used here, the choice of benchmark is unlikely to affect results materially; see Brown and Warner (1985). The market model is estimated using returns from day -170 through day -21 where day 0 is the announcement of the first bid in the WSJ. The equally weighted CRSP index is used as the market index.
} 
effects on mean premia and on success probabilities. The event-date return reflects two offsetting effects. The higher average premium a winning first bidder will have to pay given a competing bid is bad news, but the reduced probability of success resulting from a competing bid can be good news if the market expects a successful bidder to overpay. Since the intervention method disentangles these possibilities, a zero return (for example) can map into substantial value improvements.

If the market is efficient, and if no news about a competing bid arrives until the day that the bid occurs, then the abnormal return expected from date 1 (immediately after the initial bid) through date 2 (just before the competing bid) will on average be zero. Thus, equation (11), which gives $I R^{I M}$ in terms of $R_{3}$, the return from date 1 through date 3 , also applies with a return from date 2 through date 3 , or by choosing some starting date between date 1 and date 2 .

There is a tradeoff in using different periods. If news about a competing bid sometimes arrives between date 1 and 2, calculating the return based on the earlier starting point has the advantage of including the effects of such anticipation of the event. However, calculating the abnormal return over a longer period has the disadvantage of introducing noise arising from normal stock price fluctuations and from benchmark estimation errors.

We therefore estimate the return to be substituted for $R_{3}$ in (11) based on the two different periods discussed earlier: the two-day event period (mean -.43\%) and the period from immediately after announcement of the initial bid through announcement of the second bid (mean -3.58\%). We require the following further inputs (all transaction-specific except as otherwise indicated):

- $P_{1} / V_{0}^{C}$ in equation (11) is the size of the bidder relative to initial combined value. The mean (median) figure is .656 (.690).

- $V_{0}^{T} / V_{0}^{C}$ in equation (11) is the size of the target relative to combined value prior to the initial offer. The mean (median) figure is .368 (.327).

- $\phi_{1}$ is the probability of success of the first bidder. In our sample the first bidder is successful in 690 out of 1018 contests. Hence $\phi_{1}$ is estimated as 690/1018=.6778; we also use alternative transaction-specific estimates using Logit model A1 or A2 in Table 3.

- $\phi_{3}$ is the probability of success of the first bidder given the arrival of a competing bidder. In our sample, there are 147 cases in which a competing bidder arrives; the first bidder is successful in 38 instances. Hence $\phi_{3}$ is estimated as $38 / 147=.2585$; we also use alternative transaction-specific estimates using Logit model B in Table 3. 
- $\alpha$ is the fraction of the target's equity owned by the first bidder. For the 141 tender offers in our competing bid subsample to which we can apply IM, the mean (median) $\alpha$ is $2.41 \%(0 \%)$. For our whole sample of tender offers, the mean bidder ownership is $6.13 \%$, the median ownership is $0 \%$, and only 220 of the 1018 bidders own any shares in the target at the time they make the bid.

- $\bar{B}_{1} / V_{0}^{T}$ is the average price (relative to the target's pre-offer price) at which the first bidder wins in the full sample, and we also use alternative transaction-specific estimates using a regression technique. The estimate based on sample mean is 1.407.

- $\bar{B}_{3} / V_{0}^{T}$ is the average price at which the first bidder wins given the arrival of a competing bidder, and we also use alternative transaction-specific estimates using a regression technique. The estimate based on sample mean is 1.514.

\subsection{Estimated value improvements}

In the competing bid subsample, we use several alternative methods to estimate input parameters for IM. The calculations apply equation (11) using estimated parameters $\phi_{1}$, $\phi_{3}, \bar{B}_{1} / V_{0}^{T}$, and $\bar{B}_{3} / V_{0}^{T}$. When these parameters are estimated using sample means as described above (hereafter, the baseline parameter specification), the mean (median) $I R^{I M}$ is $13.1 \%(12.4 \%)$, indicating that the discounted combined value as assessed by the market is $13.1 \%$ more valuable as a result of the takeover. This evidence is inconsistent with the Strong Agency/Hubris Hypothesis of zero value improvements in tender offers. Since the distribution of $I R^{I M}$ is not especially skewed, and 132 of $141 I R^{I M} \mathrm{~S}$ are greater than zero, the conclusion that the expected value improvement is significantly greater than zero is highly robust ( $p<.001$ by a sign test). A histogram of $I R^{I M}$ is provided in Fig. 5 .

We also estimate separate transaction-specific probabilities of success using the logit model of Table 3 to obtain individual probability estimates for each of the 147 transactions. Similarly, instead of assuming that the expected bid premium that will be paid (relative to pre-offer price) in the event that the first bidder succeeds is independent of the transaction, we estimate regression models relating the price paid in successful transactions to the same independent variables used in Logit Models A1, A2, and B (excluding effective premium). This generates a corresponding set of regression models.

These results (unreported) are consistent with the conclusion that value improvements on average differ from zero and are generally positive. For example, when $\phi_{1}$ and $\phi_{3}$ are respectively estimated using Logit model A1 and A3 in Table 3 , and $\bar{B}_{1} / V_{0}^{T}$ and $\bar{B}_{3} / V_{0}^{T}$ are 
estimated using regression models similar to model A1 and B in Table 3 (excluding effective premium), the mean (median) value improvement is $14.8 \%$ (13.8\%), which is quite similar to the estimates obtained using our baseline parameter specification. Appendix B further verifies the robustness of this conclusion with respect to alternative estimates of the input parameters. In what follows, we draw our numerical inference on the IM estimate using our baseline parameter specification.

In Table 4, market-based estimates of the expected combined value improvement from takeover (relative to combined bidder-target value) are labeled $C I B R, I R^{P S M}$ and $I R^{I M}$. The average estimated CIBR associated with the arrival of an initial bid during 1962-2001 is approximately $5.27 \%$ (median of $3.69 \%$ ) of combined bidder/target value.

Using PSM, the average estimated value improvement, $I R^{P S M}$ is larger - approximately $7.28 \%$ (median of $4.63 \%$ ) of combined bidder/target value. The average difference between the $I R^{P S M}$ and CIBR estimates relative to combined value is $2.02 \%$ (median of .22\%), with $63.4 \%$ of the differences being positive.

We also use a proxy for the revelation bias, the difference $I R^{P S M}-I R^{I M} . I R^{P S M}$ reflects the change in underlying value that would be associated with takeover success, but also includes revelation effects. $I R^{I M}$ contains only the underlying value effect, not the revelation effect. The difference is therefore a proxy for the revelation bias. According to Table 4, the overall revelation bias is not significantly different from zero. However, there is variation in revelation effects across time, degree of hostility, and means of payment, as discussed further in the next Section.

\subsection{Determinants of value improvements and revelation effects}

We describe several possible determinants of value improvements, and the variables we use as proxies for these determinants. In Tables 5, 6 and 7, we present univariate results of how value improvements are related to these determinants. In Table 8, we present multivariate regression results.

\section{Friendly versus hostile offers}

Academics and other commentators have proposed two very different economic roles for takeovers - discipline/removal of bad target managers, and exploitation of business synergies. Hostile offers are supposed to be associated with removal of bad target managers, and friendly offers with exploitation of business synergies. To examine these issues we include 
the Hostile dummy defined in Section 3 as an independent variable.

\section{Cash versus mixed versus equity offers}

In general, as in Myers and Majluf (1984), issuance of equity can convey adverse information about the firm's existing assets in place. Several models of means of payment in takeovers imply an adverse selection problem associated with greater use of equity. Under an adverse selection approach, the use of cash may provide the favorable revelation that equity was not used. On the other hand, a cash offer may reveal that the firm has cash in excess of its internal investment needs, and is likely to squander that cash on poor investments should the bid fail (Jensen, 1988; Stulz, 1990). This implies a negative revelation effect. $^{27}$

\section{Same-industry versus diversifying transactions}

We define an acquisition as same-industry versus cross-industry (i.e., non-diversifying versus diversifying) according to whether the target firm has the same or a different SIC code from the bidder. We consider both 3-digit and 4-digit COMPUSTAT SIC codes.

\section{Relative market values of bidder and target}

It has been argued that so-called 'mergers of equals' are hard to implement successfully. ${ }^{28}$ This suggests that acquisitions of small targets by large bidders will tend to generate greater improvement per dollar spent on acquisition than combinations of similar-sized firms. It could also be argued that in unequal acquisitions, the business benefits of possessing the target can be 'leveraged' across a larger set of operations, again yielding greater gains per dollar spent on acquisition.

In the univariate analysis, we place transactions in four relative size categories: bidder/target market value ratio $<0.7$ (small bidder), $0.7<X<1.5$ (same relative size), $1.5<X<5.0$ (big relative size), $5.0<X$ (largest relative size). We use a continuous variable, the logarithm of relative size, in the regressions.

\section{Tobin's $Q$}

Lang, Stulz, and Walkling (1989) and Servaes (1991) found that takeover gains are related to bidder and target $Q$ ratios. Following Martin (1996), we define $Q$ as the sum of

\footnotetext{
${ }^{27} \mathrm{An}$ alternative story is that paying with cash indicates a good management that is willing to commit itself to discipline in future investments; this would imply a favorable revelation about managerial quality.

${ }^{28}$ See, e.g., The Economist, 1/9/99, page 15: "Nor does it [success] require similarity of size: mergers of equals seem to be especially tricky, perhaps because they disrupt two strong corporate cultures, and they often throw up intractable problems of leadership." (The use of the term 'mergers' in the quoted remark seems to be generic, rather than exclusive of tender offers.)
} 
market value of equity, long-term debt, short-term debt, and preferred stock divided by book value of equity, calculated as of the fiscal year-end preceding the takeover announcement date.

\section{Time dependence of value improvements}

The Williams Act of 1968 and associated legislation requiring disclosure and delaying completion of tender offers makes it easier for competitors to investigate the target after an initial bid (Jarrell and Bradley, 1980). One would expect this to narrow the set of bidders who are willing to make an initial offer. This suggests that post-Williams transactions should be associated with higher value improvements. Several authors have documented large changes in premia and several other takeover-related variables beginning at approximately this time (though explanations differ as to the source of these changes). To assess the effect of the Williams Act, we create a dummy variable for pre-Williams (7/62-6/68) and post-Williams subperiods.

In addition, commentators have claimed that the U.S. financial market environment has changed after March 2000, when the NASDAQ and several other broad stock indexes peaked. We examine whether there was a shift in value gains after March 2000 by using a dummy for pre- and post-March 2000.

\section{$\underline{\text { Results }}$}

Panels $\mathrm{A}$ and $\mathrm{B}$ of Table 5 indicate that combined returns to bidders and targets, as measured by $C I B R$ and $I R^{P S M}$, are on average considerably higher in hostile than in friendly offers. In the overall sample (Panel A), the mean CIBR of hostile offers is $8.43 \%$, versus $4.38 \%$ for friendly offers. The mean $I R^{P S M}$ of hostile offers is $16.34 \%$, versus $4.75 \%$ for friendly offers. For both measures, the difference between hostile and friendly offers is significant at the $1 \%$ level. However, Table 5 indicates that hostile bidders earn lower announcement period returns than friendly bidders. ${ }^{29}$ Target announcement period returns in hostile offers are also not higher than in friendly offers. This suggests that hostile bidders that are large (small) relative to targets earn higher (lower) announcement period returns.

The difference between friendly and hostile offers is much larger for $I R^{P S M}$ than for $C I B R$ because hostile bids are less likely to succeed. In consequence, the traditional CIBR method biases returns toward zero more for hostile bids more than for friendly bids. Thus, the probability scaling method indicates an even greater difference between friendly and hostile bids than what is indicated by traditional methods. Large friendly/hostile differences in

\footnotetext{
${ }^{29}$ The Hostile coefficient in the bidder CAR regression in Table 8 is negative but not significant at conventional levels, consistent with Schwert (2000) and Moeller, Schlingemann and Stulz (2003a, $2003 \mathrm{~b})$.
} 
$I R^{P S M}$ are also present in the competing bid subsample of Panel B. The multivariate results in Table 8 also confirm that $I R^{P S M}$ is significantly positively related to hostility (we do not run regressions with $I R^{I M}$ as the dependent variable, owing to the small competing-bid sample size).

In contrast with the large friendly/hostile differences in $I R^{P S M}$, in Table 5, Panel B the intervention method measure $\left(I R^{I M}\right)$ indicates that hostile offers are not associated with significantly higher value improvements than friendly offers. Since $I M$ estimates filter out revelation effects, the different behavior of the $I R^{P S M}$ and $I R^{I M}$ estimates indicates that friendly and hostile offers convey different information to investors about bidder stand-alone value.

Table 5 Panel B indicates that hostility is related to a larger (more positive) revelation effect $I R^{P S M}-I R^{I M}$ (significant at the $1 \%$ level). There is a positive revelation effect of hostile offers $(6.06 \%$, significant at the $1 \%$ level), and a negative revelation effect of friendly offers $(-4.42 \%$, significant at the $1 \%$ level). The average upward revision in the market's assessment of the stand-alone value of hostile bidders is consistent with the hypothesis that hostile bids are taken by the market as an indicator of strong cash flow prospects or organizational capabilities on the part of the bidder. ${ }^{30}$ Alternatively, the negative revelation about friendly bidders and the positive revelation about hostile bidders may derive from the fact that hostile offers are more prone to be cash and friendly offers more prone to be equity or mixed payment. We discuss revelation effects associated with means of payment below.

Although there are differences in stockholder returns between friendly and hostile offers, the thrust of this evidence is that both hostile and friendly offers are associated with substantial value improvements in takeovers. Thus, overall, this evidence indicates that both disciplinary and synergistic roles for takeover are important.

Table 5 indicates an ordering in which cash offers on average create greater CIBR and $I R^{P S M}$ value improvements than mixed offers, and mixed offers greater than stock offers; most of the comparisons are significant at the $1 \%$ level. Similarly, in the multivariate analysis of Table 8, in the regressions with dependent variables $C I B R$ and $I R^{P S M}$, the coefficient on cash (equity) is significantly positive (negative).

Owing to the smaller sample sizes in Panel B, there is less power to detect differences. Nevertheless, a pattern that emerges clearly is that the value improvement difference between equity and mixed-payment offers is much smaller using the intervention method. In

\footnotetext{
${ }^{30}$ Despite the favorable revelation about stand-alone value, investors presumably understand that successful hostile offers can be very expensive for the bidder, so there is not presumption that the announcement period returns for hostile offers is positive; see the discussion at footnote 29.
} 
consequence, the revelation bias $I R^{P S M}-I R^{I M}$ is much more negative for stock than for cash offers (difference in means significant at the $5 \%$ level, difference in medians significant at the $1 \%$ level), and more negative for stock than for mixed offers (difference in means significant at the $10 \%$ level, difference in means significant at the $5 \%$ level). The point estimates also indicate a more negative revelation bias for mixed offers than for cash offers (substantial for medians), though the difference is not significant. In other words, greater use of equity is associated with more negative revelation about bidder stand-alone value. Thus, our evidence is consistent with the adverse selection theory's implication that the use of equity is an adverse indicator of firm value, and is not consistent with the argument that the use of cash reveals a propensity of bidding management to waste free cash flow.

A large literature debates the extent to which diversifying acquisitions are associated with more severe bidder agency problems. The agency theory of diversification suggests both lower true value improvements, and certainly lower bidder returns, in cross-industry transactions than same-industry transactions. The data provide support for the notion that same-industry acquisitions create greater value than cross-industry acquisitions. In Table 6, bidder returns and value improvement measures are generally lower in diversifying acquisitions. The evidence for bidder returns extends the conclusions of Morck, Shleifer and Vishny (1990) to the turn of the millennium. The finding for combined value improvements indicates that the lower bidder returns in diversifying acquisitions do not derive solely from redistribution to targets. The results also indicate that the greater gains to same-industry acquisitions identified in stock mergers by Maquieira, Megginson and Nail (1998) also applies in tender offers. Similarly, in the multivariate analysis of Table 8, the coefficient estimates for the same-industry dummy are significantly positive for most of the value measure columns.

Our findings provide an interesting contrast with those of Moeller, Schlingemann and Stulz (2003a, 2003b), who find diversification to be insignificant as a predictor of bidder announcement period returns in public acquisitions. ${ }^{31}$

Although Table 6 indicates that same-industry acquisition are generally associated with higher bidder and combined returns than cross-industry acquisitions, Panel B indicates that $I R^{I M}$ is about the same in the two groups, indicating similar value improvements from combination. The $I R^{P S M}-I R^{I M}$ block indicates the reason: same-industry acquisitions are associated with more favorable revelation than cross-industry acquisitions. This suggests that investors perceive diversifying acquisitions as indicating that management is prone to

\footnotetext{
${ }^{31}$ As discussed earlier, the sample of Moeller, Schlingemann and Stulz (2003a, 2003b) includes mergers as well as tender offers, and our study covers a longer sample period. Also, they define industry using SDC SIC codes, whereas we define industries using Compustat SIC's. Kahle and Walkling (1996) provide evidence suggesting that Compustat SIC codes are better specified than CRSP SIC codes.
} 
agency problems such as wasteful investment, whereas same-industry acquisitions indicate managerial discipline and expertise. These results do not indicate any great pessimism on the part of investors about the value of combination in diversifying transactions. Rather, they indicate that the low returns associated with these transactions derive from adverse updating about the quality of the bidder and its management.

Table 7 shows that acquisitions in which the bidder is relatively large compared to the target improve value (as a fraction of combined value) significantly less. The regression results in Table 8 confirm this finding: value improvement measures are inversely related to the relative size of the bidder versus the target. In contrast, when takeover gains are measured relative to the value of the target (not reported here), the mean estimated improvement is largest when a target is acquired by a much larger bidder. Despite concerns raised in the business press about so-called 'mergers of equals,' it is not clear from these two pieces of evidence that parity of bidder and target size in a tender offer is a bad thing.

Previous research on relative size has focused on its effects on bidder returns. Asquith, Bruner and Mullins (1983) found that merger bidder returns are decreasing with the relative size of the bidder versus target. In a recent sample, Moeller, Schlingemann and Stulz (2003a) report that after controlling for bidder size, relative size is unrelated to the returns of bidders acquiring public firms. Our evidence indicates that relative size is also related to total (combined) value improvements.

If the gains from combination are derived solely from target improvements such as removal of bad management, then a larger relative size of the bidder would not increase the gains relative to the size of the target. Thus, our finding suggests that there are gains from combination involving synergies between bidder and target. Something about the targetperhaps a unique technology - can be 'leveraged' to provide a firm-wide benefit to the bidder. On the other hand, the fact that greater relative size of the bidder implies smaller value gains relative to combined value suggests that there are limits to this leveraging. To some extent the gains do seem to come from changes specific to the target rather than general synergies.

To investigate how value improvements are related to bidder and target Tobin's $Q$ ratios, we run value improvement regressions, including $Q$ ratios in the list of independent variables, as well as separate regressions of bidder and target returns on takeover characteristics. The results are reported in the last four columns of Table 8. Bidder announcement period returns (CAR) and total value improvements are negatively related to bidder $Q$, and target announcement period CAR is negatively related to target $Q$. The effect of $Q$ in our sample is economically significant. In Table 8, the coefficient of bidder $Q$ is -0.38 , meaning for an increase of 1 unit of bidder $Q$, bidder return decreases by $-0.38 \%$. Since the standard 
deviation of $Q$ is 3.26 (the average bidder $Q$ is 1.88), $Q$ is associated with non-negligible variation in return.

Our bidder returns finding is consistent with the fact (e.g., Travlos, 1987; Brown and Ryngaert, 1991; Fuller, Netter, and Stegemoller, 2002; Moeller, Schlingemann, and Stulz, 2003a, 2003b) that stock bidders have lower announcement period returns, since stock bidders tend to have higher $Q$ (Martin, 1996) and lower book/market ratios (e.g., Dong et al, 2003).

However, this finding is quite different from those of Lang, Stulz, and Walkling (1989) and Servaes (1991). In their earlier sample, bidder returns were higher when high $Q$ bidders acquired low $Q$ targets. The difference in results suggests that the takeover boom of the 1990s had a different character from that of the 1980s. Our finding also contrasts with that of Moeller, Schlingemann, and Stulz (2003a, 2003b) that there is no economically significant relation between bidder $Q$ and returns in acquisitions of public firms. Their sample differs from ours in several ways. It includes only successful acquisitions, includes merger bids as well as tender offers, and covers a shorter time period than our sample.

Also, Table 8 indicates that higher target Tobin's $Q$ is associated with lower target announcement stock returns. This is consistent with recent findings for target book-market ratios; see Dong et al (2003), and with earlier findings of Lang, Stulz and Walkling (1989) and Servaes (1991).

Based on Table 4, it appears that 1989-92 was a period of unusually low value improvements from takeover (based on $C I B R$ and $I R^{P S M_{-}}$the sample size for $I R^{I M}$ for this period is too small to be meaningful). There is no indication that the takeover boom of the mid1990s was associated with high percentage value improvements. Based on our estimates, the dollar value increase associated with the mid-1990s transactions was large. However, transactions in the late 1990s and the post-March 2000 period were associated with large wealth losses, due to the tremendous value losses to some relatively large bidders. These results are broadly consistent with the findings of Moeller, Schlingemann, and Stulz (2003a) (whose focus was on absolute bidder size).

In Table 5, it appears that value improvements were higher prior to than subsequent to the Williams Act. However, based on Table 8, there is no significant difference between the pre- and post-Williams Amendment periods under any of the two value improvement measures. This suggests that the difference in takeover gains between these subperiods found in Table 5 was likely due to shifts in takeover characteristics that are captured as explanatory variables in the multivariate analysis, such as a relatively high proportion of cash offers and smaller bidders prior to the Williams Act.

Table 5 also indicates that there was a massive increase in target announcement period 
abnormal returns in the post-March 2000 period: from $28.77 \%$ to $44.78 \%$ (means), and from $25.30 \%$ to $39.81 \%$ (medians). This finding is reinforced by the target return regression in Table 8, in which the coefficient on the Post-March 2000 category variable is substantial $(11.24, t=3.24)$. This indicates that the increase in target returns goes above and beyond what would be predicted by shifts in the regression explanatory variables.

Table 5 also indicates (significant with the PSM measure) that, after March 2000, combined returns (CIBR and $\left.I R^{P S M}\right)$ decreased. In contrast, the first two regressions in Table 8 suggest that combined returns increased after March 2000. However, as the next two regressions indicate, after controlling for bidder and target Tobin's $Q$ 's, the post-March 2000 dummy is not significant for CIBR or $I R^{P S M}$. These findings indicate that the postMarch 2000 decrease in combined returns can be explained fully by shifts in the explanatory variables.

\section{Do bidders pay too much?}

To measure over- or under- payment, it is convenient to measure bid premia relative to combined bidder/target value, according to the overpayment condition (2). The results in Table 9 highlight that the new methods have an important effect on inferences. If we estimate value improvements using CIBR, the combined abnormal stock return, we find that in the competing bid sub-sample, bidders on average significantly overpaid, by $5.1 \%$ (median 3.0\%), with almost $65 \%$ of the 135 observations indicating overpayment. This difference is significant at the $1 \%$ level. However, as we have argued, CIBR captures only a fraction of the total takeover gains, and is subject to revelation bias. Using either the intervention method or the probability scaling method, the mean value improvement is not statistically different from the mean premium paid in these multiple bidder offers. So we cannot reliably reject the null that the payment is on average fair. In the competing bid sub-sample, both of the new methods developed here indicate that about half of the 135 initial bidders overpaid. Since value improvements are large, it appears that most of the bid premia can be explained by value improvements. ${ }^{32}$

\footnotetext{
${ }^{32}$ There is a possible sample selection bias in the intervention method. The intervention method examines initial bidder returns when a competing bidder enters, but if the initial bidder offers too much on his first bid, this will tend to discourage competitors from arriving. Thus, a bidder who offers a very generous initial offer may not end up in the multiple-bidder sample. On the other hand, other things equal, the arrival of a competitor raises the amount that a first bidder with given valuation will have to pay. Thus, we doubt that there is more overpayment in single-bidder contests than in multiple bidder contests. This view is consistent with evidence on competitors' stock returns (see BDK-88).
} 


\subsection{Robustness of IM, PSM and traditional measures to window length}

All of the methods we apply are influenced by the length of the window selected. To evaluate whether the value improvements derived by IM and PSM are higher than those implied by traditional approaches, it is therefore of interest to consider different window lengths.

Using traditional methods, with a day -5 to +5 window where date 0 is the date of the initial bid, the mean (median) weighted average of the bidder and target returns using value weights is $5.27 \%$ (3.69\%), with $71 \%$ of the returns being positive; see Table 2, Panel A. In the older sample of BDK-88, the mean initial return relative to combined market value is $6.93 \%$. Thus, there was a decline in mean returns in the decade following the BDK study.

A reasonable starting point that would account for pre-public-announcement anticipation of the event would be in the order of 30 to 40 days; see, e.g., Fig. 1 of Schwert (1996). Using a longer window that begins 30 days prior to the initial offer and runs through final announcement of the transaction, we obtain a mean (median) bidder and target weighted return of $7.12 \%$ ( $6.35 \%$ ). The corresponding measure beginning 90 days prior to the initial offer is $6.65 \%(7.05 \%)$.

The combined CARs for these initial returns for different windows are summarized in Table 2, Panel B. Even with long event windows prior to the event, the mean CAR based on the initial bid is at most only $7.1 \%$, as compared with $13.1 \%$ using the intervention method. ${ }^{33}$ These results imply that the gains from takeover are considerably greater than the (already substantial) gains estimated in previous studies.

Furthermore, the use of a $(-1,0)$ window by $I M$ for the arrival of the competing bid also potentially misses some runup. In unreported results, we find that a longer pre-competingbid window is associated with even higher $I R^{I M}$ estimate.

\subsection{Robustness with respect to model specifications}

\section{Competing bidder information}

As mentioned in Section 2.4, the arrival of a competing bid may convey information about either the stand-alone value of the target or its value to the initial bidder- a different kind of revelation effect. Footnotes 18 and 19 argue this is likely to have only a minor

\footnotetext{
${ }^{33}$ The use of a long window such as 60 or 90 days is probably suboptimal. While such a window ensures that any pre-event information leakage is captured in the return, it also greatly increases noise. In this case, as we lengthen the window the mean CAR increases up to a 30 day window. But moving from a 15 to a 30 day window leads to a smaller fraction of positive abnormal returns, suggesting that the problem of noise starts to become severe in the longer window.
} 
effect on IM estimation. More importantly, the intervention method mitigates this problem relative to previous studies by focusing on competing bids, since it is likely that much of the private information possessed by bidders about targets will already be conveyed by the initial offer.

If the arrival of a competing bid causes an upward revision in the assessed valuation of the first bidder, then ceteris paribus the first bidder's abnormal return $R_{3}$ will be higher. By constraining $\bar{V}_{3}=\bar{V}_{1}$, our estimates would tend to wrongly attribute any such higher abnormal return to the reduced probability of the initial bidder succeeding. Thus, the estimated value improvement would be biased downwards, providing a conservative estimate. Thus, the inference that takeovers are on average associated with positive underlying value improvements is strengthened.

To analyze this issue directly, suppose that $\bar{V}_{3}^{I}=K \bar{V}_{1}^{I}, K \geq 1$, i.e., the arrival of a competing bid causes an upward revision in the assessed valuation by the first bidder of owning the target. We abbreviate $\bar{V}_{1}^{I}$ as $\bar{V}^{I}$ in the following. Substituting into equations (7), (8), and (9), and solving gives

$$
\frac{\bar{V}^{I}}{V_{0}^{C}}=\frac{R_{3}\left(P_{1} / V_{0}^{C}\right)}{K \phi_{3}-\phi_{1}}-(1-\alpha)\left(\frac{\phi_{3}-\phi_{1}}{K \phi_{3}-\phi_{1}}\right)\left(\frac{V^{T}}{V_{0}^{C}}\right)+(1-\alpha)\left(\frac{V^{T}}{V_{0}^{C}}\right) \frac{\left[\phi_{3}\left(\frac{\bar{B}_{3}}{V_{0}^{T}}\right)-\phi_{1}\left(\frac{\bar{B}_{1}}{V_{0}^{T}}\right)\right]}{K \phi_{3}-\phi_{1}} .
$$

As suggested Section $2.4, K$ is likely to be close to one. The implied $I R^{I M}$ estimates, which are increasing in $K$, are provided in the first two columns of Table 10. This simulation supports the conclusion of positive average value improvements; large values of $K$ lead to implausibly high values for $\bar{V}^{I} / V_{0}^{C}$.

\section{Future acquisitions}

The basic analysis assumed that success or failure of the offer has no effect on any future acquisitions that the bidder may make. More generally, if the first bidder fails to acquire the target, there is a probability that it will thereafter successfully acquire a similar target at a price similar to what he would have paid if he had been successful in acquiring the original target. If so, the stock price reaction to failure of the initial bid will be muted. Of course, a bidder whose offer fails is not certain to make an additional acquisition as a consequence of failure. ${ }^{34}$ We model this possible dependence by allowing for some probability that failure of the offer will cause the bidder to try to acquire another comparable target at the same

\footnotetext{
${ }^{34}$ There is no difficulty if the bidder intends to make other acquisitions regardless of the outcome of the first contest. The calculation of the stock price reaction associated with the arrival of a competing bid needs modification only if future acquisitions depend on the success or failure in the current contest.
} 
expected price. ${ }^{35}$ Suppose that value improvements in takeovers are positive. Then when the arrival of a competing bid reduces the probability of success, the bidder actually has a good chance of succeeding in another acquisition, so the actual bidder return will be greater than that implied by the basic model of Section 4. This higher return implies that $I R^{I M}$ will underestimate the actual improvement. Similarly, if value improvements are negative, $I R^{I M}$ will overestimate the improvement. So long as failure may lead to another comparable acquisition, the basic method biases $I R^{I M}$ toward zero, but leaves its sign unchanged. ${ }^{36} \mathrm{~A}$ robustness check is provided by reestimating $I R^{I M}$ 's in a model in which, given failure, there is a probability $\gamma$ that the bidder will make another acquisition attempt of equal quality to the first.

Suppose that the first bidder can find another identical target with probability $\gamma$ after failure to acquire the first target. Then equations (9) and (11) become

$$
\begin{aligned}
& \bar{\pi}_{1}=\left[\phi_{1}+\gamma \phi_{1}\left(1-\phi_{1}\right)\right]\left[\alpha \bar{V}^{I}+(1-\alpha)\left(\bar{V}^{I}+V_{0}^{T}-\bar{B}_{1}\right)\right] \\
& \bar{\pi}_{3}=\left[\phi_{3}+\gamma \phi_{1}\left(1-\phi_{3}\right)\right]\left[\alpha \bar{V}^{I}+(1-\alpha)\left(\bar{V}^{I}+V_{0}^{T}-\bar{B}_{3}\right)\right]
\end{aligned}
$$

So

$$
\frac{\bar{V}^{I}}{V_{0}^{C}}=\frac{R_{3}\left(P_{1} / V_{0}^{C}\right)}{\delta_{2}}-(1-\alpha)\left(\frac{V_{0}^{T}}{V_{0}^{C}}\right)+(1-\alpha)\left[\left(\frac{\delta_{1}+\delta_{2}}{\delta_{2}}\right)\left(\frac{\bar{B}_{3}}{V_{0}^{T}}\right)-\left(\frac{\delta_{1}}{\delta_{2}}\right)\left(\frac{\bar{B}_{1}}{V_{0}^{T}}\right)\right]\left(\frac{V_{0}^{T}}{V_{0}^{C}}\right),
$$

where $\delta_{1} \equiv \phi_{1}\left[1+\gamma\left(1-\phi_{1}\right)\right]$, and $\delta_{2} \equiv\left(\phi_{1}-\phi_{3}\right)\left(\gamma \phi_{1}-1\right)$. IR $R^{I M}$ decreases as a function of $\gamma$, but the effect is weak. As shown in columns 3 and 4 of Table 10, the estimated value improvement is still positive and substantial for plausible values of $\gamma$. The effect of $\gamma$ on $I R^{I M}$ would be stronger if, after a second failure, the bidder again had a probability of turning to a third target and so on.

\section{Sale of shares to another bidder}

We now allow for the possibility that an unsuccessful initial bidder can sometimes profit by selling his holdings to a successful competing bidder. Let $\operatorname{Pr}\left(S^{2} \mid \theta\right)$ denote the probability

\footnotetext{
${ }^{35}$ There are several possible reasons why this probability is less than one. First, alternative targets may seem less attractive to bidding management. For example, under Roll's hubris hypothesis, a bidder's first offer will be to the target he overvalues the most. Second, a manager may change his mind about the desirability of acquisition. Third, he may retire or be replaced before he locates another target. Fourth, if acquisition is undesirable, the initial offer may rouse large shareholders or the board to oppose further attempts.

${ }^{36}$ More generally, the sign could be incorrect, but this requires a rather special scenario. For example, if the improvement is always zero in the initial contest, but after an initial failure the bidder always makes a negative NPV acquisition, then the stock return will be lower than the calculation in Section 4 . The negative stock return, in combination with the reduction in probability of success associated with the arrival of a competing bid, would tend to be attributed to a positive value improvement.
} 
of arrival and success of the second bidder, and let $\beta$ denote the expected winning bid of the second bidder. Then so long as $\beta>V_{0}^{T}$ (so that it pays for the unsuccessful initial bidder to sell to the later bidder),

$$
\begin{aligned}
& \bar{\pi}_{1}=\phi_{1}\left[\alpha \bar{V}^{I}+(1-\alpha)\left(\bar{V}^{I}+V_{0}^{T}-\bar{B}_{1}\right)\right]+\alpha \operatorname{Pr}\left(S^{2} \mid \theta_{1}\right)\left(\beta-V_{0}^{T}\right) \\
& \bar{\pi}_{3}=\phi_{3}\left[\alpha \bar{V}^{I}+(1-\alpha)\left(\bar{V}^{I}+V_{0}^{T}-\bar{B}_{3}\right)\right]+\alpha \operatorname{Pr}\left(S^{2} \mid \theta_{3}\right)\left(\beta-V_{0}^{T}\right) .
\end{aligned}
$$

So

$$
\begin{aligned}
\frac{\bar{V}^{I}}{V_{0}^{C}}= & \frac{R_{3}\left(P_{1} / V_{0}^{C}\right)}{\phi_{3}-\phi_{1}}-(1-\alpha) \frac{V_{0}^{T}}{V_{0}^{C}}+(1-\alpha) \frac{\left[\phi_{3}\left(\bar{B}_{3} / V_{0}^{T}\right)-\phi_{1}\left(\bar{B}_{1} / V_{0}^{T}\right)\right]}{\phi_{3}-\phi_{1}}\left(\frac{V_{0}^{T}}{V_{0}^{C}}\right) \\
& -\left\{\frac{\alpha\left(\frac{\beta}{V_{0}^{T}}-1\right)\left[\operatorname{Pr}\left(S^{2} \mid \theta_{3}\right)-\operatorname{Pr}\left(S^{2} \mid \theta_{1}\right)\right]}{\phi_{3}-\phi_{1}}\right\}\left(\frac{V_{0}^{T}}{V_{0}^{C}}\right) .
\end{aligned}
$$

As a rough approximation we replace $\beta$ with our estimates of the expected price paid by a successful first bidder conditional on the arrival of a competing bidder, $\bar{B}_{3}$. The unconditional probability of a second bidder winning is the probability that a second bidder arrives multiplied by the probability given arrival that the second bidder wins, $\operatorname{Pr}\left(S^{2} \mid \theta_{1}\right)=$ $\operatorname{Pr}$ (Competing Bid Occurs) $\operatorname{Pr}\left(S^{2} \mid \theta_{3}\right)$. $\operatorname{Pr}$ (Competing Bid Occurs) is estimated as 147/1018. Thus, only one of the other two probabilities is a free variable. $I R^{I M}$ for different possible values of $\operatorname{Pr}\left(S^{2} \mid \theta_{3}\right)$ are given in columns 5-7 of Table 10. A benchmark value for this variable is .5, the case in which, given the arrival of a competing bidder, the first and second bidder have equal probabilities of winning. Column 6 gives the estimated improvement ratio with the bidders' actual initial shareholdings in the target. Column 7 provides alternative numbers assuming larger initial shareholdings. For plausible parameter values, the estimated value improvement is robust with respect to the possibility of sale of the initial bidder's toehold.

\section{Valuation/success correlation}

Finally, the success of the initial bidder is likely to be positively correlated with the value improvement, because a high valuation first bidder will probably be willing to offer more. The logit-based probability estimates, which generated similar results to simple estimates based on ex post sample fractions addresses this issue to the extent that explanatory logit variables such as the initial bid premium are correlated with the first bidder's valuation. In any case, the potential bias is a subtle one, because IM estimates are based on the change in probability of success when a competing bid occurs. Even if probabilities were misestimated across transactions, it is not clear that there would be any important, systematic 
misestimation in the changes in probabilities. ${ }^{37}$

Similarly, it can plausibly be argued that if improvements are common across bidders, a high value improvement increases the probability of a competing bid arrives. Again, the potential bias implied by this effect is subtle, because the ex ante probability of a competing bid is overestimated for some contests and underestimated for others. ${ }^{38}$ It therefore seems unlikely that these effects would have much effect on inferences about value improvements.

In summary, several robustness checks with respect to several possible modelling variants confirm that the conclusion of positive average value improvements provided using the basic model is highly robust. For plausible parameter values, all estimates of the average value improvement are positive and substantial.

\section{$5 \quad$ Summary and conclusions}

Despite an extensive literature, the issue of whether tender offers increase or decrease combined average bidder and target value has remained unresolved. Past stock market based studies have provided valuable information consistent with positive average improvements. However, the conventional event study approach is subject to two important estimation problems. The first, the truncation dilemma, arises when the announcement of the event does not ensure successful completion of the event. This forces the investigator to choose between truncated event windows that measure only a part of the value effect of a successful transaction, and long-windows that introduce severe noise and benchmark errors.

The second problem is that event-related returns are infected with a bidder revelation bias (Bradley, Desai and Kim, 1983; Jensen and Ruback, 1983; Roll, 1986; Jovanovic and Braguinsky, 2002). Tender offer bids are sometimes announced concurrently with other disclosures; and a bid may in itself reveal information about the value of the bidder not

\footnotetext{
${ }^{37}$ The most plausible presumption is probably that the arrival of a competitor has a smaller impact on probability of success when the valuation is high. Then for a high valuation first bidder, the drop in probability of success is overestimated, which implies that $I R^{I M}$ is an underestimate. (Because the negative abnormal return is attributed excessively to the drop in probability of success rather than to a large value improvement.) Conversely, for low (but positive) valuation firms, the drop in probability of success is underestimated, so that $I R^{I M}$ is an overestimate. Under these conditions this potential bias changes the relative magnitude of $I R^{I M}$ for different firms, but it does not imply any obvious bias in overall sample averages.

${ }^{38}$ If the true improvement is high, the arrival of a competing bid would be less of a surprise than our calculations indicate. For such contests, the improvement is underestimated. On the other hand, if the true improvement is low, the arrival of a competing bid would be more of a surprise than our calculations indicate. For such contests, the improvement is overestimated. The effect on overall sample averages is unclear.
} 
arising from the combination, such as the bidder's stand-alone cash flow prospects or the empire-building propensities of management.

This paper estimates whether and by how much tender offers are perceived by investors as improving combined equity value. We offer an approach to estimating perceived value improvements, the probability scaling method, that addresses the truncation dilemma. Furthermore, we offer an approach that addresses both the truncation dilemma and the bidderrevelation bias. This approach, the intervention method, is based on a model of the stock returns of an initial bidder when a competing bid occurs.

We apply both the traditional method and the two new methods to a sample of tender offers during 1962-2001. Perceived value improvements are much larger than traditional methods indicate. As a result, even though the conventional method indicates that bidders on average overpay, using our new methods we cannot reject the hypothesis that bidders on average pay fair prices for targets.

Furthermore, traditional methods can lead to incorrect inferences about economic forces in the takeover market. We identify several effects (higher combined bidder-target stock returns for hostile offers, lower for equity offers, and lower for diversifying offers) that reflect differences in revelation about stand-alone value, not gains from combination.

We also identify some factors that do affect the gains from combination, not just revelation about stand-alone value. Using all three approaches, acquisition of a smaller target by a large bidder on average creates a smaller value improvement, measured as a fraction of combined value, than combinations of similar-sized firms. But measured relative to the value of the target, the mean estimated improvement is larger for such transactions. These findings are consistent with the importance of both synergies and target-specific improvements such as removal of bad management.

Furthermore, bidder announcement period returns and total value improvements are negatively related to bidder Tobin's $Q$ (in contrast with evidence from the earlier samples of Lang, Stulz, and Walkling (1989) and Servaes (1991)). Target announcement period returns are negatively related to target $Q$, consistent with previous literature.

All else equal, the evidence of positive value improvements, and that improvements are larger than estimates based on traditional unadjusted returns, tends to oppose highly restrictive regulation of takeovers. There are, however, other important policy considerations, such as possible errors in market perceptions, possible redistributions of wealth from stakeholders such as customers and employees, and between different classes of securityholders, the disciplinary or distortive effects of the ex ante threat of takeover, and the ex ante costs of locating targets.

The probability scaling method and the intervention method can be applied to test the 
relation of value improvements to other possible determinants. For example, an interesting issue that could be addressed using these methods is whether the arrival of white knights blocks superior hostile acquisitions. These new methods can also potentially be applied to other corporate activities that are announced but are not always carried through, such as repurchase programs, planned asset sales, planned development of new products, acquisition programs, and many others. 


\section{Appendix A: Numerical illustration of the probability scaling and intervention methods}

The basic ideas of PSM and IM can be illustrated by numerical examples.

\section{The probability scaling method}

Consider a bidder who does not own any shares of the target. Suppose that the standalone value of the target is 100 , the stand-alone value of the bidder is 200 , and that the transaction will create a value improvement of 40. Suppose that prior to the initial bid the market assesses the probability of a bid to be close to zero, and that just after the initial bid the probability of offer success is perceived to be .6. Then the stock market's assessment of the combined bidder-target expected value prior to the initial bid is approximately

$$
100+200=300
$$

Just after the initial bid, this assessment is revised to

$$
100+200+.6(40)=324 \text {. }
$$

The combined bidder-target equity return is therefore

$$
\frac{324}{300}-1=8.0 \%
$$

This is only a fraction of the percentage value improvement associated with a completed takeover, which is $40 / 300=13 . \overline{3} \%$ of combined value.

The PSM grosses up the equity return by the probability of success, which gives the total value gain of a virtual completed transaction,

$$
\frac{8.0 \%}{.6}=13 . \overline{3} \%
$$

of combined bidder-target value.

The actual implementation of PSM also takes into account that the target return reflects the market's belief about the likelihood that the target will be acquired by any bidder, not just the first bidder. Subsection 2.3 derives PSM in detail.

\section{The revelation bias}

We now illustrate the revelation bias inherent in the conventional approach to estimating takeover value improvements. To begin with, let there be no value improvement from successful takeover, so that stand-alone and post-takeover discounted value of target cash flows are both $\$ 100$. Suppose that prior to the initial bid, the market estimates the standalone value of the bidder to be $\$ 200$. Suppose that a bid reveals favorable news to the market about stand-alone bidder value, so that the post-initial-bid market assessment of stand-alone bidder value is $\$ 250$. The $\$ 50$ discrepancy is the effect the bid has on the market's assessment of stand-alone value. 
The stock market's assessment of combined bidder-target value prior to the initial bid is

$$
100+200=300 .
$$

Just after the initial bid, this assessment is revised to

$$
100+250=350
$$

The combined bidder-target equity return will therefore be

$$
\frac{350}{300}-1 \approx 16.7 \% \text {. }
$$

If the revelation effect of the initial bid is ignored, the researcher will wrongly attribute this return to an expected value improvement of $.166 \times \$ 300=\$ 50$ (50\% of target value), when in fact the improvement is zero. As Roll (1986) pointed out, even a modest revelation bias for the bidder can create a large overestimate of the value improvement from takeover measured relative to target value, since on average bidders are much larger than targets.

\section{The intervention method}

Since competition reduces a first bidder's probability of success, ceteris paribus its stock price will drop if its value improvement is large compared to the expected price that will be paid, and rise if the value improvement is less than the expected purchase price. Thus the stock price reaction to a competing bid provides information about the value improvement. However, holding probability of success constant, competition should hurt the first bidder to the extent that he is forced to pay more when he wins. The challenge for the intervention method is to disentangle these two effects.

After the initial bid, the market's assessment of stand-alone bidder value is $\$ 250$. We will compare a case of positive value improvement, where the value of the target managed by the bidder is $\$ 140$, with the case of zero improvement, where the post-takeover NPV of target cash flows if managed by the bidder is $\$ 100$.

Positive value improvement

Suppose that at the time of the initial offer, the probability of the initial bidder succeeding is .6, but that if a competitor makes a bid, this probability is only .4. (These overall probabilities take into account the possibility that a competing bid may be forthcoming.) Suppose that at the time of the initial offer, the expected price that the first bidder will have to pay if he succeeds is $\$ 120$, but that if a competitor arrives, this expected price paid by the first bidder rises to $\$ 130$. We assume that regardless of the bidder's method of payment, the expected price ( $\$ 120$ or $\$ 130$ ) refers to the actual price paid by the bidder at the time of completion of the deal. Based on this information, the stock price of the bidder after announcing his offer rises to

$$
250+.6(140-120)=262 .
$$

If a competitor appears, the first bidder's stock price retreats to

$$
250+.4(140-130)=254 .
$$


Thus, the first bidder's stock return on the arrival of a competing bidder is $(254-262) / 262 \approx$ $-3 \%$.

The initial bidder's stock return reflects the facts that when a competing bid arrives, (1) the first bidder will have to pay more if he succeeds, and (2) the first bidder has a lower probability of succeeding. Clearly point (1) contributes negatively to the first bidder's return. Point (2) also contributes negatively to the stock return here, because a lower probability of success prevents the bidder from realizing profits. These profits are the difference between the improvement brought about by the first bidder and the expected price paid. Thus, the first bidder's stock return on the arrival of a competing bid reflects the market's assessment of the value improvement that the first bidder can bring about. Specifically, the larger the improvement, ceteris paribus, the more negative the return. And if the improvement is smaller than the expected price, then point (2) will contribute positively to the bidder's return.

Zero value improvement

These points are illustrated by making one change in the example. Suppose now that the takeover does not improve value, so the value of the target when acquired is the same as its stand-alone value of $\$ 100$. Replacing $\$ 140$ with $\$ 100$ in the above calculations shows that the bidder's stock return on the arrival of a competing bidder is $0 \%$. The negative effect of the higher price that will be paid in the event of success is offset by the positive effect of an increased probability of failure.

The intervention method uses ex post data to estimate the various parameters of this numerical example: the unconditional probability of success of an initial bidder, the probability of success given the arrival of a competitor, the unconditional expected price paid by an initial bidder given that he succeeds, and the expected price he pays if he succeeds given that a competing bid occurs. Given these parameters (along with the initial shareholding of the bidder in the target), the value improvement from the takeover implies a specific stock return for the first bidder. It is therefore possible to infer the size of the value improvement from the observed stock return.

The above discussion is based on the distinction between creation of value and revelation of information about value. It is possible that an action can create value as a direct result of revealing value; this in no way obviates the need to distinguish the two concepts. For example, if a takeover bid conveys to the market the idea that the bidder's prospects are good, customers or suppliers may be more willing to deal with the firm (e.g., Titman, 1984). If so, even a manager whose sole objective is to maximize fundamental value may expend resources in order to reveal information. Nevertheless, the value created by a corporate action is in general different from the value revealed. Generally, these quantities can have different orders of magnitude and need not have the same sign. Thus, the increase in stock price associated with a corporate action is an invalid measure of the effect of that action on underlying value. Furthermore, even if the announcement of a takeover bid makes market perceptions more favorable, and this change in perceptions in turn increased underlying value significantly, this value increase is not an actual benefit from combination, but a benefit of favorable revelation. ${ }^{39}$ The intervention method (1) accommodates, but does not

\footnotetext{
${ }^{39}$ In the numerical example above, the increase in the market's stand-alone valuation of bidder from 200 to 250 could reflect not the direct effect on expectations of more favorable information, but the fact that the bidder's higher stock price may in itself help it to generate greater cash flows as a stand-alone entity.
} 
require, possible effects of value revelation on fundamental value; (2) accommodates, but does not require signalling motivations; and (3) estimates only those value improvements that result from combination of the two firms, not those that result from revelation about stand-alone value.

\section{Appendix B: Robustness of $I M$ results with respect to alternative parameter estimates}

We analyze the robustness of the conclusion that the mean value improvement ratio is positive with respect to the parameter estimates for $\bar{R}_{3}, \phi_{1}, \phi_{3}, \bar{B}_{1} / V_{0}^{T}$, and $\bar{B}_{3} / V_{0}^{T}$. We conduct two experiments. First is a sensitivity analysis of $I R^{I M}$ with respect to the probability of success unconditionally, $\phi_{1}$, and conditional on a competing bid, $\phi_{3}$; with respect to the expected price paid unconditionally, $\bar{B}_{1} / V_{0}^{T}$, and conditional on a competing bid, $\bar{B}_{3} / V_{0}^{T}$; and with respect to the mean first bidder stock return on announcement of a competing bid, $\bar{R}_{3}$. Second, we compare our results to those implied by samples studied by Bhagat, Shleifer, and Vishny (1990) and Betton and Eckbo (2000).

We examine the effect of shifting each of these estimated parameters simultaneously in the direction of lower $I R^{I M}$. This check is stringent, since there is no reason to expect estimation errors all to boost the $I R^{I M}$. The results indicate that the conclusion that value improvements are on average positive is not very sensitive to shifts in parameter estimates. Even if all 4 of the estimated parameters are shifted by $12 \%$ of their respective mean values, the mean estimated $I R^{I M}$ remains positive. ${ }^{40}$

A limitation of the intervention method is that it provides value estimates only in those contests for which the intervention (competing bid) actually occurs. If contests that did not enter the intervention sample are different, the returns to the first bidder in such contests upon arrival of a competing bid would be systematically different from the first bidder returns in the actual competing bid sample. While it is impossible to address this issue conclusively, the conclusion of positive value improvements with respect to the estimated stock returns is extremely robust. The sensitivity to $\bar{R}_{3}$ provides an indication of whether the conclusions we derive are likely to be sample specific. We recalculated $I R^{I M_{\mathrm{S}}}$ substituting fictional alternative values for $\bar{R}_{3}$ for all first bidders. Both the mean and median value improvements remain positive even for an abnormal return as high as $+3.5 \%$, and a majority are positive even for an abnormal return as high as $+7 \%{ }^{41}$ These robustness checks support the conclusion that value improvements are on average positive and substantial.

The conclusion of positive average value improvements applies in other samples as well. Bhagat, Shleifer, and Vishny (1990) (BSV) analyze an exhaustive sample of hostile takeover contests in the U.S. during 1984 through 1986 where the purchase price was $\$ 50$ million or more. Their sample consists of 61 contests: 50 targets were acquired and 11 remained

\footnotetext{
${ }^{40}$ The probability that all 4 misestimates are in the upward direction is $(1 / 2)^{4}=.0625$; imposing the condition that the magnitudes of the misestimates be greater than $12 \%$ would reduce the probability much further.

${ }^{41}$ Intuitively, the reason that the estimates remain positive even when intervention returns are high is that the mean bid premia are very substantial. Thus, even if the value improvement is positive, if it is smaller than the expected price to be paid, the arrival of a competing bid and the associated reduction in the probability of the first bidder succeeding can be good news.
} 
independent. The first bidder was successful in 29 of the 61 contests. Competing bids were observed in 30 of the 61 contests. The first bidder prevailed in the face of a competing offer in nine instances.

The above figures indicate that in the BSV sample $\phi_{1}$, the probability of success of the first bidder in the full sample, is $29 / 61$ or .4754 . Also, $\phi_{3}$, the probability of success of the first bidder in the presence of a competing bidder, is $9 / 30$ or .3000 . Similarly, we estimate $\bar{B}_{1} / V_{0}^{T}$, and $\bar{B}_{3} / V_{0}^{T}$ implied by the BSV sample. We then substitute these parameter estimates into the $I R^{I M}$ formula transaction by transaction in our full dataset to generate an alternative set of $I R^{I M}$ 's.

The estimated input parameters from the BSV sample period (1984-6) are fairly similar to those of this study. When the BSV sample parameter estimates are substituted into the $I R^{I M}$ formula (11), the inference about $I R^{I M}$ is unchanged, that the mean $I R^{I M}$ is positive. Simultaneously substituting the BSV estimates for $\bar{B}_{1} / V_{0}^{T}, \bar{B}_{3} / V_{0}^{T}, \phi_{1}$, and $\phi_{3}$ with other mean parameters generates a mean (median) $I R^{I M}$ of $9.0(9.9)$.

Betton and Eckbo (2000) examine a sample of tender offers from 1971-1990. They report that in their sample, the unconditional probability of bidder success was .6386, and conditional on a competing bid was only .1682. The unconditional expected premium was $56.96 \%$, and conditional on a competing bid was $85.60 \%$. Applying these figures to our overall sample transaction by transaction in the $I R^{I M}$ formula gives an average $I R^{I M}$ of $17.5 \%(15.3 \%)$. This is somewhat higher than the estimates of about $13-15 \%$ using our own sample.

To summarize, in this appendix we have performed robustness checks by varying estimated parameters, both individually and simultaneously; and by using parameter estimates obtained from the BSV and the Betton and Eckbo (2000) samples. These analyses all confirm that value improvements were on average positive. 


\section{References}

Andrade, G., Mitchell, M., Stafford, E., 2001. New evidence and perspectives on mergers. Journal of Economics Perspectives 15, 103-120.

Asquith, P., Bruner, R., Mullins, Jr., D., 1983. The gains to bidding firms from merger. Journal of Financial Economics 11, 121-139.

Barber, B., Lyon, J., 1997. Detecting long-run abnormal stock returns: The empirical power and specification of test statistics. Journal of Financial Economics 43, 341-372.

Betton, S., Eckbo, B.E., 2000. Toeholds, bid jumps, and expected payoffs in takeovers. Review of Financial Studies 13,841-882.

Bhagat, S., Shleifer A., Vishny, R., 1990. Hostile takeovers in the 1980's: The return to corporate specialization. Brookings Papers on Economic Activity, 1-72.

Bradley, M., Desai A., Kim, E.H., 1983. The rationale behind inter-firm tender offers: Information or synergy? Journal of Financial Economics 11, 141-153.

Bradley, M., Desai A., Kim, E.H., 1988. Synergistic gains from corporate acquisitions and their division between stockholders of target and acquiring firms. Journal of Financial Economics $21,3-40$.

Brown, D.T., Ryngaert, M.D., 1991. The mode of acquisition in takeovers: Taxes and asymmetric information. Journal of Finance 46, 653-669.

Brown, S.J., Warner, J.B., 1985. Using daily stock returns: The case of event studies. Journal of Financial Economics 14, 3-32.

Bulow, J., M. Huang and P. Klemperer, 1999, Toeholds and Takeovers, Journal of Political Economy 107, 427-454.

Comment, R. Jarrell, G., 1987. Two-tier and negotiated tender offers: The imprisonment of the free-riding shareholder. Journal of Financial Economics 19, 283-310.

Dodd, P., Warner, J.B., 1983. On corporate governance: A study of proxy contests. Journal of Financial Economics 11, 401-438.

Dong, M., Hirshleifer, D., Richardson, S., Teoh, S.H., 2003. Does investor misvaluation drive the takeover market? Unpublished working Paper, Ohio State University.

Eckbo, B.E., 1983. Horizontal mergers, collusion and stockholder wealth. Journal of Financial Economics 11, 241-273.

Eckbo, B.E., 1992. Mergers and the value of antitrust deterrence. Journal of Finance 47, 1005-1029.

Eckbo, B.E., Giammarino, R., Heinkel, R., 1990. Asymmetric information and the medium of exchange in takeovers: Theory and evidence. Review of Financial Studies 3, 651-76.

Fishman, M., 1988. A theory of pre-emptive takeover bidding. Rand Journal of Economics 19, 88-101. 
Fishman, M.J., 1989. Preemptive bidding and the role of medium of exchange in acquisitions. Journal of Finance 44, 41-58.

Franks, J., Harris, R., Titman, S., 1991. The post-merger share-price performance of acquiring firms. Journal of Financial Economics 29, 81-96.

Fuller, K., Netter, J., Stegemoller, M., 2002. What do returns to acquiring firms tell us? Evidence from firms that make many acquisitions. Journal of Finance 57, 1763-1793.

Grossman, S., Hart, O., 1980. Takeover bids, the free-rider problem, and the theory of the corporation. Bell Journal of Economics 11, 42-64.

Hansen, R.G., 1987. A theory for the choice of exchange medium in mergers and acquisitions. Journal of Business 60, 75-95.

Healy, P.M., Palepu, K.G., Ruback, R.S., 1992. Does corporate performance improve after mergers? Journal of Financial Economics 31, 135-175.

Hirshleifer, D., Titman, S., 1990. Share tendering strategies and the success of hostile takeover bids. Journal of Political Economy 92, 295-324.

Jarrell, G., and Bradley, M., 1980. The economic effects of federal and state regulations of cash tender offers. Journal of Law and Economics 23, 371-407.

Jarrell, G., Brickley, J., Netter, J., 1988. The market for corporate control: The empirical evidence since 1980. Journal of Economic Perspectives 2, 49-68.

Jennings, R.H., Mazzeo, M.A., 1993. Competing bids, target management resistance, and the structure of takeover bids. Review of Financial Studies 6, 883-910.

Jensen, M., 1988. Takeovers: Their causes and consequences. Journal of Economic Perspectives 2, $21-48$.

Jensen, M., Ruback, R., 1983. The market for corporate control: The scientific evidence. Journal of Financial Economics 11, 5-50.

Jovanovic, B., Braguinsky, S., 2002. Bidder discounts and target premia in takeovers. NBER working paper 9009.

Kahle, K., Walkling, R., 1996. The impact of industry classifications on financial research. Journal of Financial and Quantitative Analysis 31, 309-335.

Kaplan, S., Weisbach, M., 1991. The success of acquisitions: Evidence from divestitures. Journal of Finance 47, 107-138.

Kothari, S.P., Warner, J., 1997, Measuring long-horizon security price performance, Journal of Financial Economics 43, 301-339.

Lang, L., Stulz, R., Walkling, R., 1989. Managerial performance, Tobin's q, and the gains from successful tender offers, Journal of Financial Economics 24, 137-154.

Loughran, T.,Vijh, A., 1997. Do long-term shareholders benefit from corporate acquisitions? Journal of Finance 52, 1765-1790.

Maquieira, C.P., Megginson, W.L., and Nail, L., 1998. Wealth creation versus wealth redistributions in pure stock-for-stock mergers. Journal of Financial Economics 48, 3-33. 
Martin, K.J., 1996. The method of payment in corporate acquisitions, investment opportunities, and management ownership. Journal of Finance 51, 1227-1246.

Mitchell, M., Stafford, E., 2000. Managerial decisions and long-term stock price performance. Journal of Business 73, 287-320.

Moeller, S., Schlingemann, F., Stulz, R., 2003a. Do shareholders of acquiring firms gain from acquisitions? Journal of Financial Economics, forthcoming.

Moeller, S., Schlingemann, F., Stulz, R., 2003b. Wealth destruction on a massive scale? A study of acquiring-firm returns in the merger wave of the late 1990s. Unpublished working Paper, Ohio State University.

Morck, R., Shleifer A., Vishny, R., 1990. Do managerial objectives drive bad acquisitions? Journal of Finance 45, 31-48.

Mueller, D., 1985. Mergers and market share. Review of Economics and Statistics 47, 259-267.

Myers, S., Majluf, N., 1984. Corporate financing and investment decisions when firms have information that investors do not have. Journal of Financial Economics 13, 187-221.

Palepu, K., 1986. Predicting takeover targets: A methodological and empirical analysis. Journal of Accounting and Economics 8, 3-35.

Ravid, S.A., Spiegel, M., 1999. Toehold strategies, takeover laws and rival bidders. Journal of Banking and Finance 23, 1219-1242.

Rau P., Vermaelen, T., 1998. Glamour, value and the post-acquisition performance of acquiring firms. Journal of Financial Economics 49, 223-254.

Roll, R., 1986. The hubris hypothesis of corporate takeovers. Journal of Business 59, 197-216.

Schipper, K., Thompson, R., 1983. Evidence on the capitalized value of mergers activity for acquiring firms. Journal of Financial Economics 11, 85-119.

Schwert, G.W., 1996. Markup pricing in mergers and acquisitions. Journal of Financial Economics 41, 153-92.

Schwert, G.W., 2000. Hostility in takeovers: In the eyes of the beholder? Journal of Finance 55, 2599-2640.

Servaes, H., 1991. Tobin's Q and the gains from takeovers. Journal of Finance 46, 409-419.

Shleifer, A., Vishny, R., 1986. Large shareholders and corporate control. Journal of Political Economy $96,461-488$.

Shleifer, A., Vishny, R., 2003. Stock market driven acquisitions. Journal of Financial Economics, forthcoming.

Stulz, R., 1990. Managerial discretion and optimal financing policies. Journal of Financial Economics $26,3-27$.

Titman, S., 1984. The effect of capital structure on a firm's liquidation decision. Journal of Financial Economics 13, 137-52. 
Travlos, N.G., 1987. Corporate takeover bids, method of payment, and bidding firms' stock returns. Journal of Finance 42, 943-963.

Walkling, R., 1985. Predicting tender offer success: A logistic analysis. Journal of Financial and Quantitative Analysis 20, 461-478. 

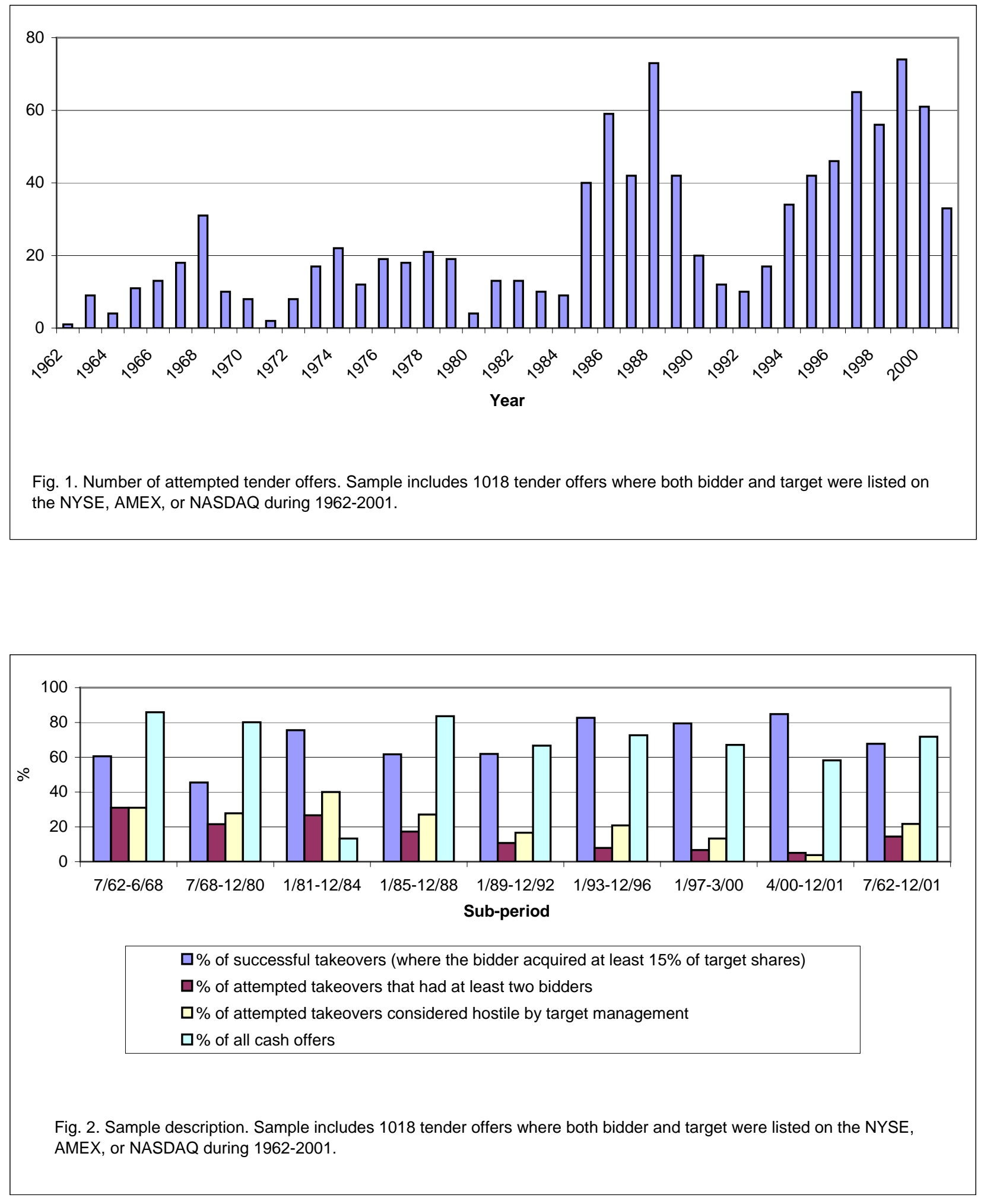

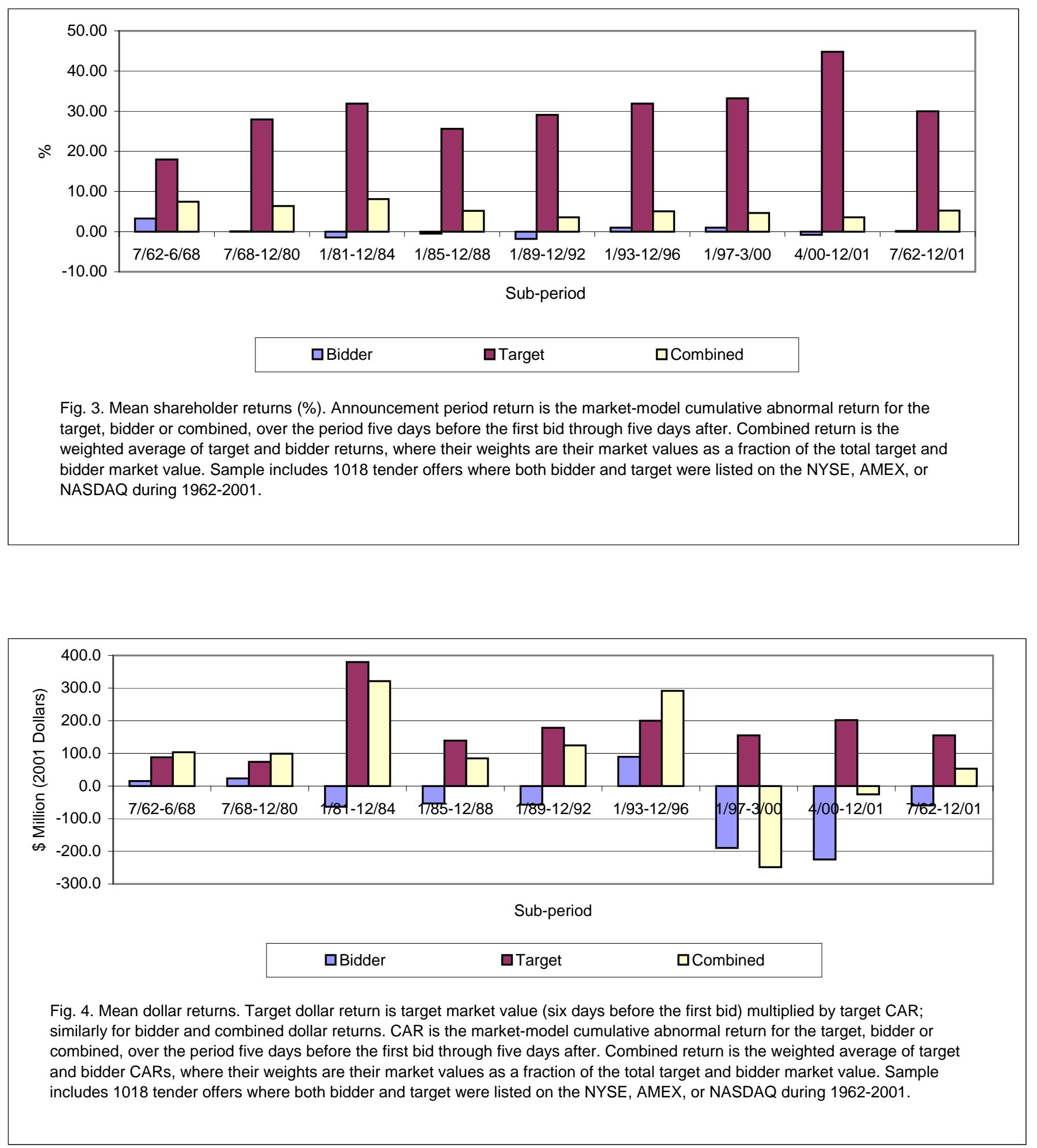

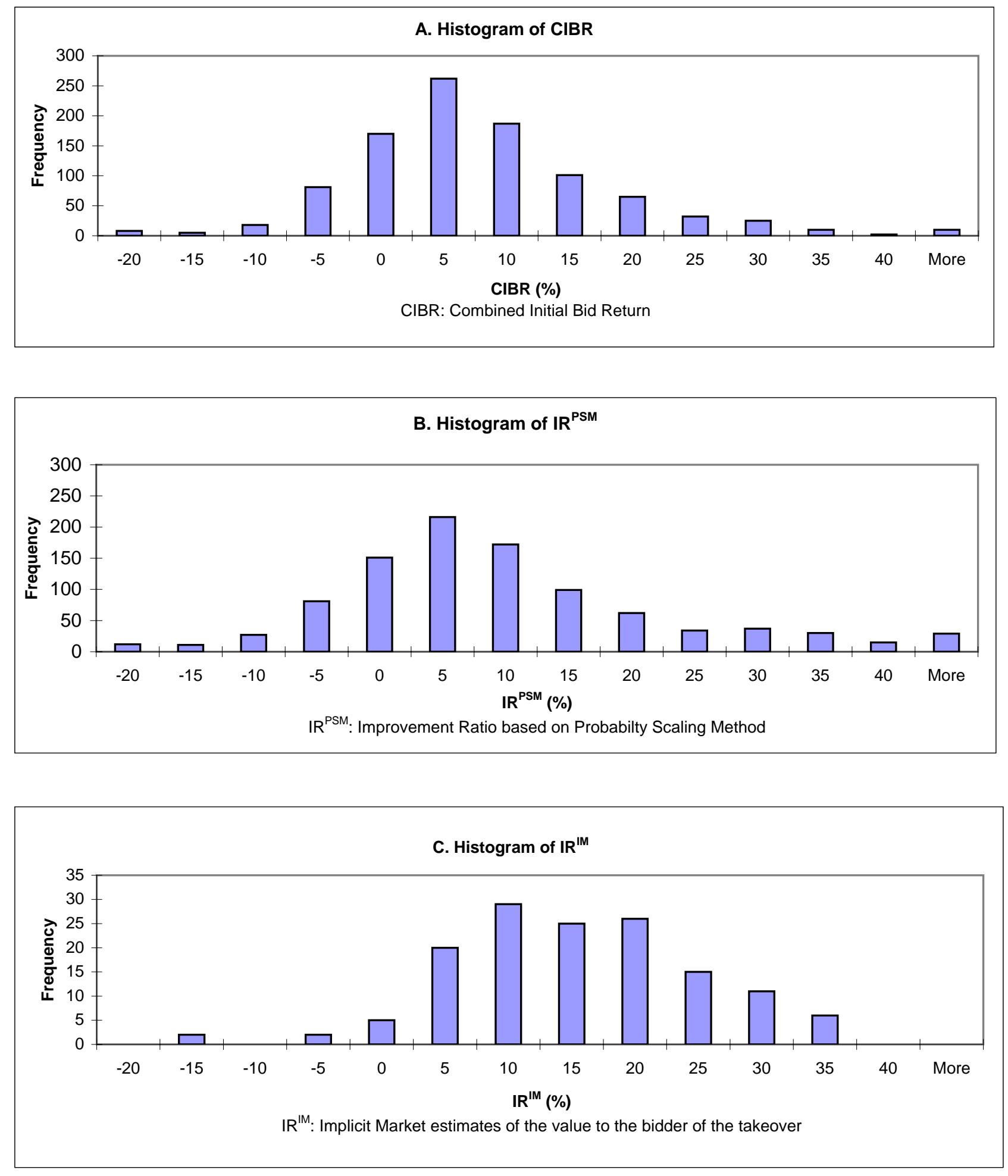

Fig. 5. Histograms of value improvement measures. Sample includes 1018 tender offers where both bidder and target were listed on the NYSE, AMEX, or NASDAQ during 1962-2001; additionally, for $\mathrm{IR}^{\mathrm{IM}}$ the sample is restricted to cases where there was a competing bid for the target. 
Table 1

Summary statistics of tender offer sample

Number of attempted offers, successful offers, offers that involved two or more bidders, offers that were considered as hostile by target management, and offers in which the target litigated against the acquisition attempt. Sample includes tender offers where both bidder and target were listed on the NYSE, AMEX, or NASDAQ during 1962-2001.

\begin{tabular}{|c|c|c|c|c|c|c|}
\hline Year & $\begin{array}{c}\text { Number of } \\
\text { attempted tender } \\
\text { offers }\end{array}$ & $\begin{array}{c}\text { Number of } \\
\text { successful offers } \\
\text { (where the bidder } \\
\text { acquired at least } \\
15 \% \text { of target } \\
\text { shares) }\end{array}$ & \begin{tabular}{|c|} 
Number of \\
attempted \\
offers that had \\
at least two \\
bidders
\end{tabular} & $\begin{array}{c}\text { Number of } \\
\text { attempted offers } \\
\text { considered } \\
\text { hostile by target } \\
\text { management }\end{array}$ & $\begin{array}{c}\text { Number of } \\
\text { attempted offers } \\
\text { where the target } \\
\text { litigated }\end{array}$ & $\begin{array}{c}\text { Number of all } \\
\text { cash offers }\end{array}$ \\
\hline 1962 & 1 & 0 & 0 & 0 & 0 & 1 \\
\hline 1963 & 9 & 5 & 1 & 2 & 0 & 9 \\
\hline 1964 & 4 & 3 & 0 & 1 & 0 & 4 \\
\hline 1965 & 11 & 9 & 1 & 2 & 1 & 10 \\
\hline 1966 & 13 & 7 & 2 & 4 & 1 & 12 \\
\hline 1967 & 18 & 8 & 11 & 8 & 4 & 16 \\
\hline 1968 & 31 & 20 & 13 & 9 & 8 & 16 \\
\hline 1969 & 10 & 6 & 3 & 1 & 2 & 4 \\
\hline 1970 & 8 & 6 & 0 & 2 & 3 & 6 \\
\hline 1971 & 2 & 2 & 0 & 0 & 0 & 1 \\
\hline 1972 & 8 & 5 & 0 & 1 & 2 & 6 \\
\hline 1973 & 17 & 6 & 2 & 4 & 5 & 16 \\
\hline 1974 & 22 & 9 & 5 & 6 & 5 & 21 \\
\hline 1975 & 12 & 5 & 3 & 3 & 9 & 11 \\
\hline 1976 & 19 & 8 & 3 & 6 & 6 & 17 \\
\hline 1977 & 18 & 8 & 5 & 3 & 4 & 18 \\
\hline 1978 & 21 & 6 & 5 & 6 & 7 & 14 \\
\hline 1979 & 19 & 8 & 4 & 11 & 9 & 16 \\
\hline 1980 & 4 & 2 & 2 & 2 & 1 & 4 \\
\hline 1981 & 13 & 5 & 9 & 10 & 8 & 3 \\
\hline 1982 & 13 & 12 & 0 & 2 & 3 & 2 \\
\hline 1983 & 10 & 9 & 2 & 4 & 2 & 0 \\
\hline 1984 & 9 & 8 & 1 & 2 & 0 & 1 \\
\hline 1985 & 40 & 19 & 7 & 12 & 15 & 29 \\
\hline 1986 & 59 & 38 & 8 & 14 & 15 & 51 \\
\hline 1987 & 42 & 32 & 5 & 9 & 12 & 38 \\
\hline 1988 & 73 & 43 & 17 & 23 & 29 & 61 \\
\hline 1989 & 42 & 24 & 6 & 11 & 15 & 31 \\
\hline 1990 & 20 & 12 & 1 & 1 & 5 & 15 \\
\hline 1991 & 12 & 8 & 2 & 1 & 8 & 3 \\
\hline 1992 & 10 & 8 & 0 & 1 & 3 & 7 \\
\hline 1993 & 17 & 13 & 2 & 2 & 6 & 11 \\
\hline 1994 & 34 & 25 & 4 & 9 & 10 & 30 \\
\hline 1995 & 42 & 36 & 3 & 12 & 13 & 30 \\
\hline 1996 & 46 & 41 & 2 & 6 & 6 & 30 \\
\hline 1997 & 65 & 46 & 8 & 13 & 5 & 38 \\
\hline 1998 & 56 & 46 & 2 & 6 & 5 & 42 \\
\hline 1999 & 74 & 65 & 4 & 6 & 4 & 53 \\
\hline 2000 & 61 & 51 & 1 & 5 & 1 & 37 \\
\hline 2001 & 33 & 26 & 3 & 1 & 0 & 17 \\
\hline $1962-2001$ & 1018 & 690 & 147 & 221 & 232 & 731 \\
\hline
\end{tabular}


Table 2

Panel A: Shareholder returns in attempted tender offers

Shareholder returns over various sub-periods in attempted tender offers. Sample includes 1018 tender offers where both bidder and target were listed on the NYSE, AMEX, or NASDAQ during 1962-2001. All dollar figures are in millions of 2001 dollars.

\begin{tabular}{|c|c|c|c|c|c|c|c|c|c|}
\hline & \multicolumn{8}{|c|}{ Sub-period } & \multirow{2}{*}{$\begin{array}{c}\text { Total } \\
7 / 62- \\
12 / 01 \\
\end{array}$} \\
\hline & $\begin{array}{l}7 / 62- \\
6 / 68 \\
\end{array}$ & $\begin{array}{l}7 / 68- \\
12 / 80 \\
\end{array}$ & $\begin{array}{l}1 / 81- \\
12 / 84 \\
\end{array}$ & $\begin{array}{l}1 / 85- \\
12 / 88\end{array}$ & $\begin{array}{l}1 / 89- \\
12 / 92\end{array}$ & $\begin{array}{l}1 / 93- \\
12 / 96\end{array}$ & $\begin{array}{l}1 / 97- \\
3 / 00\end{array}$ & $\begin{array}{l}4 / 00- \\
12 / 01 \\
\end{array}$ & \\
\hline $\begin{array}{l}\text { Number of attempted } \\
\text { tender offers }\end{array}$ & 71 & 176 & 45 & 214 & 84 & 139 & 210 & 79 & 1018 \\
\hline \multicolumn{10}{|c|}{ Bidder } \\
\hline Mean CAR (\%) & 3.29 & 0.05 & -1.42 & -0.49 & -1.78 & 0.98 & 0.97 & -0.81 & 0.18 \\
\hline Z-statistic & 5.47 & 0.48 & -1.74 & -1.00 & -3.00 & 1.22 & 1.83 & -1.01 & 0.91 \\
\hline Median CAR (\%) & 1.62 & -0.17 & -1.72 & -1.15 & -1.04 & 0.91 & -0.30 & -0.56 & -0.30 \\
\hline$\%$ positive & 63.6 & 48.8 & 31.8 & 44.4 & 41.7 & 52.9 & 48.3 & 46.8 & 47.8 \\
\hline Binomial $\mathrm{p}$ & 0.04 & 0.81 & 0.02 & 0.12 & 0.16 & 0.55 & 0.68 & 0.65 & 0.17 \\
\hline Mean dollar return & 15.1 & 23.3 & -63.4 & -53.4 & -56.9 & 89.5 & -190.0 & -225.0 & -59.2 \\
\hline Median dollar return & 9.9 & -0.7 & -6.8 & -2.9 & -8.1 & 4.0 & -2.0 & -3.6 & -1.2 \\
\hline \multicolumn{10}{|c|}{ Target } \\
\hline Mean CAR (\%) & 17.96 & 27.97 & 31.90 & 25.61 & 29.08 & 31.92 & 33.18 & 44.78 & 30.01 \\
\hline Z-statistic & 29.65 & 49.62 & 28.71 & 51.06 & 30.97 & 40.10 & 46.70 & 27.17 & 110.39 \\
\hline Median CAR (\%) & 17.79 & 22.99 & 31.61 & 21.89 & 28.25 & 29.27 & 29.46 & 39.81 & 26.10 \\
\hline$\%$ positive & 94.0 & 93.6 & 93.3 & 93.0 & 89.2 & 94.2 & 96.2 & 97.4 & 94.0 \\
\hline Binomial $\mathrm{p}$ & 0.00 & 0.00 & 0.00 & 0.00 & 0.00 & 0.00 & 0.00 & 0.00 & 0.00 \\
\hline Mean dollar return & 87.9 & 74.0 & 379.7 & 138.9 & 178.2 & 200.0 & 155.0 & 201.9 & 155.0 \\
\hline Median dollar return & 51.2 & 32.3 & 91.1 & 37.3 & 27.9 & 44.1 & 46.2 & 47.2 & 41.2 \\
\hline \multicolumn{10}{|c|}{ Combined (CIBR) } \\
\hline Mean CAR (\%) & 7.45 & 6.40 & 8.12 & 5.19 & 3.59 & 5.05 & 4.61 & 3.57 & 5.27 \\
\hline Z-statistic & 10.60 & 11.64 & 8.04 & 11.73 & 4.48 & 8.78 & 8.31 & 2.25 & 23.57 \\
\hline Median CAR (\%) & 6.42 & 4.20 & 8.22 & 3.97 & 1.76 & 4.04 & 2.93 & 3.00 & 3.69 \\
\hline$\%$ positive & 87.3 & 73.0 & 75.0 & 71.7 & 59.8 & 77.4 & 68.1 & 58.7 & 71.1 \\
\hline Binomial $\mathrm{p}$ & 0.00 & 0.00 & 0.00 & 0.00 & 0.10 & 0.00 & 0.00 & 0.17 & 0.00 \\
\hline Mean dollar return & 103.3 & 99.0 & 321.3 & 84.6 & 124.3 & 291.6 & -248.6 & -25.3 & 53.1 \\
\hline Median dollar return & 77.9 & 26.7 & 44.2 & 22.8 & 5.4 & 55.5 & 35.4 & 21.3 & 32.0 \\
\hline
\end{tabular}

$C A R$ is the market-model cumulative abnormal return for the target, bidder, or combined, over the period five days before the first bid through five days after.

Target dollar return is target market value (six days before the first bid) times target CAR; similarly for bidder and combined dollar returns.

Combined CAR (CIBR) is a weighted average of target and bidder CARs, where their weights are their market values as a fraction of the total target and bidder market value.

Combined dollar return is the sum of target and bidder dollar returns. The target mean dollar return and the bidder mean dollar return in the above table may not exactly sum to the combined dollar return because of missing data for target or bidder in some cases.

Binomial $p$ is the significance level for the two-tail Fisher sign test that tests whether the median CAR is different from zero. 
Table 2

Panel B: Longer-window shareholder returns in attempted tender offers

Shareholder returns over various (longer) windows in attempted tender offers. Sample includes 1018 tender offers where both bidder and target were listed on the NYSE, AMEX, or NASDAQ during 1962-2001.

\begin{tabular}{|c|c|c|c|c|c|c|c|}
\hline & \multicolumn{7}{|c|}{$\begin{array}{l}\text { Window: From } T \text { days prior } \\
\text { to the first bid announcement through one day after }\end{array}$} \\
\hline & $\mathbf{T}=\mathbf{9 0}$ & $\mathbf{T}=\mathbf{6 0}$ & $\mathbf{T}=\mathbf{3 0}$ & $T=15$ & $\mathbf{T}=\mathbf{1 0}$ & $\mathbf{T}=\mathbf{5}$ & $\mathbf{T}=\mathbf{1}$ \\
\hline \multicolumn{8}{|c|}{ Bidder } \\
\hline Mean CAR (\%) & -0.15 & 0.22 & 1.11 & 0.95 & 0.83 & 0.70 & 0.28 \\
\hline Z-statistic & 0.81 & 0.96 & 2.81 & 2.94 & 2.96 & 3.24 & 2.31 \\
\hline Median CAR (\%) & 0.26 & 0.68 & 0.42 & 0.43 & 0.31 & 0.16 & 0.08 \\
\hline$\%$ positive & 50.4 & 51.3 & 51.2 & 53.0 & 52.1 & 50.6 & 50.7 \\
\hline Binomial p & 0.82 & 0.43 & 0.47 & 0.06 & 0.19 & 0.73 & 0.68 \\
\hline \multicolumn{8}{|c|}{ Target } \\
\hline Mean CAR (\%) & 38.92 & 38.47 & 36.39 & 33.06 & 31.27 & 28.89 & 24.47 \\
\hline Z-statistic & 49.88 & 59.90 & 78.67 & 98.00 & 110.17 & 133.64 & 172.45 \\
\hline Median CAR (\%) & 37.04 & 35.35 & 32.79 & 29.01 & 28.21 & 24.68 & 20.07 \\
\hline$\%$ positive & 88.2 & 91.5 & 93.9 & 94.8 & 93.9 & 95.0 & 93.5 \\
\hline Binomial p & 0.00 & 0.00 & 0.00 & 0.00 & 0.00 & 0.00 & 0.00 \\
\hline \multicolumn{8}{|c|}{ Combined (CIBR) } \\
\hline Mean CAR (\%) & 6.65 & 6.88 & 7.12 & 6.23 & 5.88 & 5.32 & 4.28 \\
\hline Z-statistic & 11.28 & 13.49 & 18.68 & 22.26 & 24.90 & 29.42 & 36.57 \\
\hline Median CAR (\%) & 7.05 & 7.09 & 6.35 & 4.76 & 4.44 & 3.75 & 2.95 \\
\hline$\%$ positive & 62.9 & 67.2 & 70.7 & 72.6 & 73.4 & 72.4 & 74.8 \\
\hline Binomial $\mathrm{p}$ & 0.00 & 0.00 & 0.00 & 0.00 & 0.00 & 0.00 & 0.00 \\
\hline
\end{tabular}

$C A R$ is the market-model cumulative abnormal return for the target, bidder, or combined, over the period $\mathrm{T}$ days before the first bid through one day after.

Combined CAR (CIBR) is a weighted average of target and bidder CARs, where their weights are their market values as a fraction of the total target and bidder market value.

Binomial $p$ is the significance level for the two-tail Fisher sign test that tests whether the median CAR is different from zero. 
Table 3

Logit model estimates of the probability of success of the first bidder

Logit model estimates of the probability of success of the first bidder unconditionally (Models A1 and A2), and conditional on whether a competing bid occurs (Model B). Sample size is 1018, and includes tender offers during 1962-2001 where both target and bidder were listed on NYSE, AMEX or NASDAQ.

\section{$\underline{\text { Model A1 }}$}

\begin{tabular}{|l|c|c|}
\hline \multicolumn{1}{|c|}{ Independent Variable } & Coefficient & p-value \\
\hline Litigation & -.488 & .012 \\
\hline Hostile & -1.655 & .000 \\
\hline Alpha & -.349 & .432 \\
\hline Effective premium & .011 & .000 \\
\hline Relative size & .003 & .052 \\
\hline Constant & .936 & .000 \\
\hline
\end{tabular}

Pseudo-R2 $=.1460$. Percentage predicted $=76.8 \%$

$\underline{\text { Model A2 }}$

\begin{tabular}{|l|c|c|}
\hline \multicolumn{1}{|c|}{ Independent Variable } & Coefficient & p-value \\
\hline Hostile & -1.885 & .000 \\
\hline Alpha & -.449 & .309 \\
\hline Effective premium & .011 & .000 \\
\hline Relative size & .003 & .042 \\
\hline Constant & .881 & .000 \\
\hline
\end{tabular}

Pseudo-R2 $=.1408$. Percentage predicted $=75.4 \%$

Model B

\begin{tabular}{|l|c|c|}
\hline \multicolumn{1}{|c|}{ Independent Variable } & Coefficient & p-value \\
\hline Litigation & -.321 & .114 \\
\hline Competing bid & -1.751 & .000 \\
\hline Hostile & -1.404 & .000 \\
\hline Alpha & -.614 & .168 \\
\hline Effective premium & .012 & .000 \\
\hline Relative size & .002 & .100 \\
\hline Constant & 1.101 & .000 \\
\hline
\end{tabular}

Pseudo-R2 =.1969 . Percentage predicted $=79.9 \%$

Hostile $=1$, if the target management opposes the first bidder, 0 otherwise.

Alpha $=$ fraction of the target held by the first bidder.

Effective premium = initial bid price offered relative to the pre-bid market price of the target, multiplied by the percentage of target shares sought by the bidder through the tender offer.

Litigation $=1$, if the target files a lawsuit against the first bidder, 0 otherwise.

Competing bid $=1$, if a competing bidder arrives, 0 otherwise.

Relative size = bidder pre-bid market value relative to target pre-bid market value excluding bidder's toehold. 
Table 4

Panel A: Value improvement measures and comparisons by sub-periods

Implicit market estimates of the value improvement as a result of the takeover (IR $\left.{ }^{\mathrm{IM}}\right)$, combined initial bid returns (CIBR), and probability-adjusted combined initial bid returns (IR ${ }^{\mathrm{PSM}}$ ). Sample includes tender offers where both bidder and target were listed on the NYSE, AMEX, or NASDAQ during 1962-2001; additionally, for IR ${ }^{\mathrm{IM}}$ the sample is restricted to cases where there was a competing bid for the target. All improvement ratios are expressed as a $\%$ of target and bidder market values.

\begin{tabular}{|c|c|c|c|c|c|c|c|c|c|}
\hline & \multicolumn{8}{|c|}{ Sub-period } & \multirow{2}{*}{$\begin{array}{l}\text { Total } \\
7 / 62 \\
12 / 01 \\
\end{array}$} \\
\hline & $\begin{array}{c}7 / 62- \\
6 / 68 \\
\end{array}$ & $\begin{array}{l}7 / 68- \\
12 / 80 \\
\end{array}$ & $\begin{array}{l}1 / 81- \\
12 / 84 \\
\end{array}$ & $\begin{array}{l}1 / 85- \\
12 / 88 \\
\end{array}$ & $\begin{array}{l}1 / 89- \\
12 / 92 \\
\end{array}$ & $\begin{array}{l}1 / 93- \\
12 / 96\end{array}$ & $\begin{array}{c}1 / 97- \\
3 / 00\end{array}$ & $\begin{array}{l}4 / 00- \\
12 / 01 \\
\end{array}$ & \\
\hline \multicolumn{10}{|c|}{$\mathbf{I R}^{\mathrm{IM}}$} \\
\hline Mean (\%) & 15.62 & 12.90 & 12.09 & 14.48 & 11.54 & 10.86 & 10.49 & 10.98 & 13.05 \\
\hline Median (\%) & 15.79 & 12.33 & 8.51 & 14.26 & 9.24 & 9.99 & 9.70 & 11.48 & 12.38 \\
\hline$\%$ positive & 100.0 & 100.0 & 91.7 & 89.2 & 88.9 & 90.9 & 85.7 & 100.0 & 93.6 \\
\hline Binomial p & 0.00 & 0.00 & 0.01 & 0.00 & 0.04 & 0.01 & 0.01 & 0.13 & 0.00 \\
\hline Sample size & 18 & 36 & 12 & 37 & 9 & 11 & 14 & 4 & 141 \\
\hline \multicolumn{10}{|c|}{ CIBR } \\
\hline Mean (\%) & 7.45 & 6.40 & 8.12 & 5.19 & 3.59 & 5.05 & 4.61 & 3.57 & 5.27 \\
\hline Median (\%) & 6.42 & 4.20 & 8.22 & 3.97 & 1.76 & 4.04 & 2.93 & 3.00 & 3.69 \\
\hline$\%$ positive & 87.3 & 73.0 & 75.0 & 71.7 & 59.8 & 77.4 & 68.1 & 58.7 & 71.1 \\
\hline Binomial p & 0.00 & 0.00 & 0.00 & 0.00 & 0.10 & 0.00 & 0.00 & 0.17 & 0.00 \\
\hline Sample size & 63 & 159 & 44 & 212 & 82 & 137 & 204 & 75 & 976 \\
\hline \multicolumn{10}{|c|}{ IR $^{\text {IM }}-$ CIBR } \\
\hline Mean (\%) & 7.06 & 4.94 & -3.30 & 3.21 & 6.53 & 7.43 & 0.66 & 9.05 & 4.04 \\
\hline Median (\%) & 8.57 & 4.53 & -2.37 & 3.71 & 7.36 & 8.37 & 2.66 & 4.47 & 3.74 \\
\hline$\%$ positive & 83.3 & 66.7 & 41.7 & 56.8 & 77.8 & 72.7 & 64.3 & 50.0 & 64.5 \\
\hline Binomial p & 0.01 & 0.07 & 0.77 & 0.51 & 0.18 & 0.23 & 0.42 & 1.00 & 0.00 \\
\hline Sample size & 18 & 36 & 12 & 37 & 9 & 11 & 14 & 4 & 141 \\
\hline \multicolumn{10}{|c|}{ IR $^{\text {PSM }}$} \\
\hline Mean $(\%)$ & 11.01 & 8.86 & 13.24 & 7.82 & 5.07 & 6.38 & 5.82 & 3.82 & 7.28 \\
\hline Median (\%) & 8.42 & 5.49 & 8.82 & 5.16 & 2.07 & 5.19 & 3.22 & 3.17 & 4.63 \\
\hline$\%$ positive & 87.3 & 73.0 & 75.0 & 71.7 & 59.8 & 77.4 & 68.1 & 58.7 & 71.1 \\
\hline Binomial p & 0.00 & 0.00 & 0.00 & 0.00 & 0.10 & 0.00 & 0.00 & 0.17 & 0.00 \\
\hline Sample size & 63 & 159 & 44 & 212 & 82 & 137 & 204 & 75 & 976 \\
\hline \multicolumn{10}{|c|}{$I^{\text {PSM }}-$ CIBR } \\
\hline Mean (\%) & 3.57 & 2.46 & 5.12 & 2.63 & 1.47 & 1.33 & 1.21 & 0.25 & 2.02 \\
\hline Median (\%) & 1.25 & 0.46 & 1.08 & 0.35 & 0.01 & 0.38 & 0.10 & 0.00 & 0.22 \\
\hline$\%$ positive & 81.0 & 63.5 & 75.0 & 67.0 & 51.2 & 74.5 & 56.9 & 42.7 & 63.4 \\
\hline Binomial $\mathrm{p}$ & 0.00 & 0.00 & 0.00 & 0.00 & 0.19 & 0.00 & 0.00 & 0.09 & 0.00 \\
\hline Sample size & 63 & 159 & 44 & 212 & 82 & 137 & 204 & 75 & 976 \\
\hline \multicolumn{10}{|c|}{ IR $^{\text {PSM }}$ - IR IM (Estimated Revelation Bias) } \\
\hline Mean $(\%)$ & -2.75 & -2.14 & 17.25 & 5.10 & -1.53 & -6.65 & 6.11 & -7.88 & 1.67 \\
\hline Median (\%) & -4.98 & -1.71 & 15.90 & 2.94 & -5.35 & -5.45 & 4.79 & -3.88 & 1.10 \\
\hline$\%$ positive & 44.4 & 44.4 & 83.3 & 62.2 & 44.4 & 27.3 & 57.1 & 50.0 & 52.5 \\
\hline Binomial p & 0.81 & 0.62 & 0.04 & 0.19 & 1.00 & 0.23 & 0.79 & 1.00 & 0.61 \\
\hline Sample size & 18 & 36 & 12 & 37 & 9 & 11 & 14 & 4 & 141 \\
\hline
\end{tabular}

Binomial $p$ is the significance level for the two-tail Fisher sign test that tests whether the median is different from zero.

$\mathrm{CIBR}=$ Combined Initial Bid Return $=$ target CAR* (target market value/target and bidder market values) + bidder

CAR * (bidder market value/target and bidder market values). CAR is the market-model cumulative abnormal return for the target or bidder over the period five days before the first bid through five days after.

$\mathrm{IR}^{\mathrm{PSM}}=(\mathrm{CIBR}) /($ Probability the first bidder succeeds unconditionally + Probability a later bidder succeeds $)$. The probability of success of the first bidder is estimated from Logit model A2 in Table 3 . The probability a later bid succeeds is estimated from Betton-Eckbo (2000), and is .1463.

Parameter inputs for $\mathrm{IR}^{\mathrm{IM}}$ are estimated using sample means (the baseline specification). 
Table 4

Panel B: Value improvement measures and comparisons with different parameter specifications Implicit market estimates of the value improvement as a result of the takeover $\left(\mathrm{IR}^{\mathrm{IM}}\right)$, combined initial bid returns (CIBR), and probability-adjusted combined initial bid returns ( $\left.\mathrm{IR}^{\mathrm{PSM}}\right)$. Sample includes tender offers where both bidder and target were listed on the NYSE, AMEX, or NASDAQ during 1962-2001; additionally, for IR ${ }^{\mathrm{IM}}$ the sample is restricted to cases where there was a competing bid for the target. All improvement ratios are expressed as a $\%$ of target and bidder market values.

\begin{tabular}{|c|c|c|}
\hline & $\begin{array}{l}\text { Parameter inputs for } \mathrm{IR}^{\mathrm{IM}} \text { are } \\
\text { derived from regression/logit } \\
\text { models } \mathrm{A} 1 \text { and } \mathrm{B} \text { in Table } 3\end{array}$ & $\begin{array}{c}\text { Parameter inputs for } \mathrm{IR}^{\mathrm{IM}} \text { are } \\
\text { sample means }\end{array}$ \\
\hline \multicolumn{3}{|c|}{$\mathrm{IR}^{\mathrm{IM}}$} \\
\hline Mean $(\%)$ & 14.76 & 13.05 \\
\hline Median (\%) & 13.81 & 12.38 \\
\hline$\%$ positive & 85.9 & 93.6 \\
\hline Binomial $\mathrm{p}$ & 0.00 & 0.00 \\
\hline Sample size & 135 & 141 \\
\hline \multicolumn{3}{|c|}{ CIBR } \\
\hline Mean (\%) & 5.27 & 5.27 \\
\hline Median $(\%)$ & 3.69 & 3.69 \\
\hline$\%$ positive & 71.1 & 71.1 \\
\hline Binomial $\mathrm{p}$ & 0.00 & 0.00 \\
\hline Sample size & 976 & 976 \\
\hline \multicolumn{3}{|c|}{$I^{I M}-C I B R$} \\
\hline Mean $(\%)$ & 5.69 & 4.04 \\
\hline Median (\%) & 5.04 & 3.74 \\
\hline$\%$ positive & 66.7 & 64.5 \\
\hline Binomial $\mathrm{p}$ & 0.00 & 0.00 \\
\hline Sample size & 135 & 141 \\
\hline \multicolumn{3}{|c|}{$\mathbf{I R}^{\mathrm{PSM}}$} \\
\hline Mean (\%) & 7.28 & 7.28 \\
\hline Median (\%) & 4.63 & 4.63 \\
\hline$\%$ positive & 71.1 & 71.1 \\
\hline Binomial $\mathrm{p}$ & 0.00 & 0.00 \\
\hline Sample size & 976 & 976 \\
\hline \multicolumn{3}{|c|}{$I^{P S M}$ - CIBR } \\
\hline Mean (\%) & 2.02 & 2.02 \\
\hline Median (\%) & 0.22 & 0.22 \\
\hline$\%$ positive & 63.4 & 63.4 \\
\hline Binomial $\mathrm{p}$ & 0.00 & 0.00 \\
\hline Sample size & 976 & 976 \\
\hline \multicolumn{3}{|c|}{$\mathrm{IR}^{\mathrm{PSM}}-\mathrm{IR}^{\mathrm{IM}}$ (Estimated Revelation Bias) } \\
\hline Mean $(\%)$ & 0.28 & 1.67 \\
\hline Median (\%) & -1.06 & 1.10 \\
\hline$\%$ positive & 48.1 & 52.5 \\
\hline Binomial $\mathrm{p}$ & 0.73 & 0.61 \\
\hline Sample size & 135 & 141 \\
\hline
\end{tabular}

Binomial $p$ is the significance level for the two-tail Fisher sign test that tests whether the median is different from zero. $\mathrm{CIBR}=$ Combined Initial Bid Return $=$ target $\mathrm{CAR}^{*}$ (target market value/target and bidder market values) + bidder CAR * (bidder market value/target and bidder market values). CAR is the market-model cumulative abnormal return for the target or bidder over the period five days before the first bid through five days after.

$\mathrm{IR}^{\mathrm{PSM}}=(\mathrm{CIBR}) /($ Probability the first bidder succeeds unconditionally + Probability a later bidder succeeds $)$. The probability of success of the first bidder is estimated from Logit model A2 in Table 3. The probability a later bid succeeds is estimated from Betton-Eckbo (2000), and is .1463.

The estimated $\mathrm{IR}^{\mathrm{IM}}$ are not significantly different in the two columns at the 10 percent level. 
Table 5

The relation between value improvements and hostility, method of payment, and time periods

Implicit market estimates of the value improvement as a result of the takeover $\left(\mathrm{IR}^{\mathrm{IM}}\right)$, combined initial bid returns (CIBR), and probability-adjusted combined initial bid returns (IR ${ }^{\mathrm{PS}}$ ) for hostile/non-hostile, cash/stock/mixed, preWilliams Act (pre July 1968) / post-Williams Act, pre March 2000/post March 2000. The value improvement estimates CIBR, IR ${ }^{\mathrm{PSM}}$, and $\mathrm{IR}^{\mathrm{IM}}$ are defined in the legend of Table 4, Panel A.

Panel A: Sample includes 1018 tender offers where both bidder and target were listed on the NYSE, AMEX, or NASDAQ during 1962-2001.

\begin{tabular}{|c|c|c|c|c|c|c|c|c|c|}
\hline & Hostile & $\begin{array}{l}\text { Non- } \\
\text { Hostile }\end{array}$ & Cash & Mixed & Stock & \begin{tabular}{|c|} 
Pre- \\
Williams \\
Act \\
\end{tabular} & \begin{tabular}{|c|} 
Post- \\
Williams \\
Act \\
\end{tabular} & \begin{tabular}{|c|} 
Pre- \\
March \\
2000 \\
\end{tabular} & $\begin{array}{c}\text { Post- } \\
\text { March } \\
2000 \\
\end{array}$ \\
\hline \multicolumn{10}{|c|}{ CIBR } \\
\hline Mean (\%) & $8.43 * * *$ & $4.38 * * *$ & $5.79^{\# * * *}$ & $4.42^{\#+4+}$ & $-0.54 * 4 * * *$ & $7.45^{*}$ & $5.11 *$ & 5.41 & 3.57 \\
\hline Median (\%) & $7.06 * * *$ & $3.04 * * *$ & $4.14^{\# * * *}$ & $3.12^{\# \bullet+\bullet}$ & $-0.40^{* 4 *} * * *$ & $6.42 * * *$ & $3.52 * * *$ & $3.78 *$ & $3.00 *$ \\
\hline Sample size & 213 & 763 & 701 & 202 & 39 & 63 & 913 & 901 & 75 \\
\hline \multicolumn{10}{|c|}{ IR $^{\text {PSM }}$} \\
\hline Mean (\%) & $16.34 * * *$ & $4.75^{* * *}$ & $7.97^{\# * * *}$ & $5.83^{\#+4}$ & $-0.50^{* 4 * * * *}$ & $11.01 * *$ & $7.02 * *$ & $7.57 * *$ & $3.82 * *$ \\
\hline Median (\%) & $13.68 * * *$ & $3.27 * * *$ & $5.30^{\# * * *}$ & $3.72^{\# \bullet+\bullet}$ & $-0.45^{* 4 *} * * *$ & $8.42 * * *$ & $4.41 * * *$ & $4.78 * *$ & $3.17 * *$ \\
\hline Sample size & 213 & 763 & 701 & 202 & 39 & 63 & 913 & 901 & 75 \\
\hline \multicolumn{10}{|c|}{ Bidder CAR } \\
\hline Mean (\%) & $-0.95 * *$ & $0.49 * *$ & $0.76^{\# \# * *}$ & $-0.77^{\# \#}$ & $-2.73 * *$ & $3.29 * * *$ & $-0.04 * * *$ & 0.27 & -0.81 \\
\hline Median (\%) & $-1.15^{* *}$ & $-0.17 * *$ & $0.05^{\# \# * *}$ & $-0.78^{\# \#}$ & $-1.68 * *$ & $1.62 * * *$ & $-0.44 * * *$ & -0.29 & -0.56 \\
\hline Sample size & 214 & 782 & 716 & 205 & 41 & 66 & 930 & 917 & 79 \\
\hline \multicolumn{10}{|c|}{ Target CAR } \\
\hline Mean (\%) & 28.80 & 30.35 & $31.60^{\# * * *}$ & $28.26^{\# \bullet+4}$ & $12.35^{* * 4} * * *$ & $17.96 * * *$ & $30.86^{* * *}$ & $28.77 * * *$ & $44.78 * * *$ \\
\hline Median (\%) & 25.99 & 26.10 & $28.14^{\# * * *}$ & $25.52^{\#+4}$ & $11.52^{*+* * * *}$ & $17.79 * * *$ & $28.01 * * *$ & $25.30 * * *$ & $39.81 * * *$ \\
\hline Sample size & 220 & 787 & 723 & 205 & 44 & 67 & 940 & 929 & 78 \\
\hline
\end{tabular}

$*, * *, * * *$ indicate significant difference between the two sub-groups (hostile/non-hostile, cash/stock, pre-/ postWilliams Act, pre-/post-March 2000) at the 10\%, 5\%, 1\% levels, respectively.

\#, \#\#, \#\#\# indicate significant difference between cash and mixed sub-groups at the $10 \%, 5 \%, 1 \%$ levels, respectively.

$\downarrow$ • $\downarrow$ indicate significant difference between stock and mixed sub-groups at the 10\%, 5\%, 1\% levels, respectively. 
(Table 5 continued)

Panel B: Sub-sample includes tender offers where there was a competing bid for the target.

\begin{tabular}{|c|c|c|c|c|c|c|c|c|c|}
\hline & Hostile & $\begin{array}{c}\text { Non- } \\
\text { Hostile }\end{array}$ & Cash & Mixed & Stock & \begin{tabular}{|c|} 
Pre- \\
Williams \\
Act \\
\end{tabular} & \begin{tabular}{|c} 
Post- \\
Williams \\
Act
\end{tabular} & $\begin{array}{c}\text { Pre- } \\
\text { March } \\
2000 \\
\end{array}$ & $\begin{array}{c}\text { Post- } \\
\text { March } \\
2000 \\
\end{array}$ \\
\hline \multicolumn{10}{|c|}{$\mathrm{IR}^{\mathrm{IM}}$} \\
\hline Mean $(\%)$ & 13.59 & 12.31 & 13.49 & 10.99 & 16.55 & 15.62 & 12.68 & 13.11 & 10.98 \\
\hline Median (\%) & 14.03 & 10.94 & $13.64^{\#}$ & $9.59^{\# \bullet}$ & $16.28^{\star}$ & 15.79 & 11.69 & 12.38 & 11.48 \\
\hline Sample size & 82 & 59 & 100 & 24 & 8 & 18 & 123 & 137 & 4 \\
\hline \multicolumn{10}{|c|}{ CIBR } \\
\hline Mean $(\%)$ & $10.35 *$ & $7.19 *$ & 9.52 & 7.20 & 3.72 & 8.56 & 9.08 & 9.22 & 1.94 \\
\hline Median (\%) & $10.46^{* *}$ & $6.41 * *$ & $7.81 *$ & 5.81 & $-1.18 *$ & 8.26 & 7.65 & 7.65 & 6.01 \\
\hline Sample size & 82 & 60 & 101 & 24 & 8 & 18 & 124 & 138 & 4 \\
\hline \multicolumn{10}{|c|}{$\mathrm{IR}^{\mathrm{PSM}}$} \\
\hline Mean (\%) & $19.65^{* * *}$ & $7.93 * * *$ & $15.50 *$ & 11.63 & $3.34^{*}$ & 12.87 & 14.96 & 15.03 & 3.10 \\
\hline Median (\%) & $18.30^{* * *}$ & $7.08 * * *$ & $10.64 * *$ & $6.73^{\circ}$ & $-1.21^{\star * *}$ & 9.32 & 10.50 & 10.10 & 6.60 \\
\hline Sample size & 82 & 60 & 101 & 24 & 8 & 18 & 124 & 138 & 4 \\
\hline \multicolumn{10}{|c|}{ IR $^{\text {PSM }}-$ IR $^{\text {IM }}$ (Estimated Revelation Bias) } \\
\hline Mean $(\%)$ & $6.06^{* * *}$ & $-4.42 * * *$ & $2.06 * *$ & $0.64^{\circ}$ & $-13.21^{\bullet * *}$ & -2.75 & 2.32 & 1.95 & -7.88 \\
\hline t-statistic & 2.98 & -2.75 & 1.24 & 0.18 & -2.70 & -0.81 & 1.50 & 1.36 & -0.72 \\
\hline Median (\%) & $5.42 * * *$ & $-4.01 * * *$ & $1.77 * * *$ & $-3.38^{\star \star}$ & $-11.76^{* * * * *}$ & -4.98 & 1.70 & 1.10 & -3.88 \\
\hline Binomial p & 0.02 & 0.07 & 0.37 & 0.54 & 0.29 & 0.81 & 0.47 & 0.61 & 1.00 \\
\hline Sample size & 82 & 59 & 100 & 24 & 8 & 18 & 123 & 137 & 4 \\
\hline \multicolumn{10}{|c|}{ Bidder CAR } \\
\hline Mean $(\%)$ & $-1.51 * *$ & $1.74 * *$ & -0.20 & 1.75 & -4.15 & 2.63 & -0.58 & -0.14 & 0.04 \\
\hline Median (\%) & $-1.43 * *$ & $0.71 * *$ & $-0.59 * *$ & $0.75^{* 4}$ & $-5.15^{* 4 * *}$ & 0.46 & -0.95 & -0.79 & 5.95 \\
\hline Sample size & 83 & 61 & 102 & 25 & 8 & 20 & 124 & 140 & 4 \\
\hline \multicolumn{10}{|c|}{ Target CAR } \\
\hline Mean (\%) & 30.68 & 28.48 & $31.99 * * *$ & $25.61^{* 4}$ & $8.00^{* * * * *}$ & $19.75^{* *}$ & $31.35^{* *}$ & $29.18^{*}$ & $49.89^{*}$ \\
\hline Median (\%) & $28.77 *$ & $22.40^{*}$ & $28.37^{\# * * *}$ & $21.47^{\# \bullet \bullet}$ & $3.78^{* * * * *}$ & $21.06^{* *}$ & $28.37 * *$ & 27.37 & 33.94 \\
\hline Sample size & 84 & 61 & 103 & 24 & 9 & 20 & 125 & 141 & 4 \\
\hline
\end{tabular}

The mean Estimated Revelation Bias $\left(\mathrm{IR}^{\mathrm{PSM}}-\mathrm{IR}^{\mathrm{IM}}\right)$ may not equal the difference in means between the $\mathrm{IR}^{\mathrm{PSM}}$ and $\mathrm{IR}^{\mathrm{IM}}$ entries due to different sample size for $\mathrm{IR}^{\mathrm{PSM}}$ and $\mathrm{IR}^{\mathrm{IM}}$. The median of $\mathrm{IR}^{\mathrm{PSM}}-\mathrm{IR}^{\mathrm{IM}}$ generally does not equal the difference in medians between the $\mathrm{IR}^{\mathrm{PSM}}$ and $\mathrm{IR}^{\mathrm{IM}}$ entries.

$t$-statistic is the Student's $t$ value that tests whether the mean is different from zero.

Binomial $p$ is the significance level for the two-tail Fisher sign test that tests whether the median revelation bias is different from zero.

$*, * *, * * *$ indicate significant difference between the two sub-groups (hostile/non-hostile, cash/stock, pre-/ postWilliams Act, pre-/post-March 2000) at the 10\%,5\%, 1\% levels, respectively.

$\#$, \#\#, \#\#\# indicate significant difference between cash and mixed sub-groups at the $10 \%, 5 \%, 1 \%$ levels, respectively.

$\downarrow$ ४ $\bullet$ indicate significant difference between stock and mixed sub-groups at the $10 \%, 5 \%, 1 \%$ levels, respectively. 
Table 6

The effect of diversification on value improvements

"Same industry" is measured two ways: First, the same 4-digit COMPUSTAT SIC codes for the target and bidder. Second, the same 3-digit COMPUSTAT SIC codes for the target and bidder. Implicit market estimates of the value improvement as a result of the takeover $\left(\mathrm{IR}^{\mathrm{IM}}\right)$, combined initial bid returns (CIBR), and probability-adjusted combined initial bid returns $\left(\mathrm{IR}^{\mathrm{PSM}}\right)$. These value improvement estimates are defined in the legend of Table 4 , Panel A.

Panel A: Sample includes tender offers where both bidder and target were listed on the NYSE, AMEX, or NASDAQ during 1962-2001.

\begin{tabular}{|c|c|c|c|c|}
\hline & $\begin{array}{c}\text { Same- } \\
\text { Industry } \\
\text { (4-digit) }\end{array}$ & $\begin{array}{l}\text { Cross- } \\
\text { Industry }\end{array}$ & $\begin{array}{c}\text { Same- } \\
\text { Industry } \\
\text { (3-digit) }\end{array}$ & $\begin{array}{c}\text { Cross- } \\
\text { Industry }\end{array}$ \\
\hline \multicolumn{5}{|c|}{ CIBR } \\
\hline Mean (\%) & $6.23 *$ & $4.96^{*}$ & $6.20 *$ & $4.87 *$ \\
\hline Median (\%) & $4.62 * *$ & $3.31 * *$ & $4.60 * *$ & $3.26 * *$ \\
\hline Sample size & 254 & 715 & 307 & 662 \\
\hline \multicolumn{5}{|c|}{ IR $^{\text {PSM }}$} \\
\hline Mean (\%) & 8.26 & 6.97 & 8.17 & 6.91 \\
\hline Median (\%) & $5.39 *$ & $4.12 *$ & $5.37 * *$ & $4.02 * *$ \\
\hline Sample size & 254 & 715 & 307 & 662 \\
\hline \multicolumn{5}{|c|}{ Bidder CAR } \\
\hline Mean (\%) & 0.76 & 0.00 & 0.87 & -0.11 \\
\hline Median (\%) & $0.92 * *$ & $-0.47 * *$ & $0.77 * *$ & $-0.51 * *$ \\
\hline Sample size & 260 & 729 & 314 & 675 \\
\hline \multicolumn{5}{|c|}{ Target CAR } \\
\hline Mean (\%) & 29.45 & 30.34 & 30.84 & 29.77 \\
\hline Median (\%) & 28.37 & 25.84 & $29.18 *$ & $25.19 *$ \\
\hline Sample size & 263 & 736 & 317 & 682 \\
\hline
\end{tabular}

$*, * *, * * *$ indicate significant difference between same- and cross-industry tender offers at the $10 \%, 5 \%, 1 \%$ levels, respectively. 
(Table 6 continued)

Panel B: Sub-sample includes tender offers where there was a competing bid for the target.

\begin{tabular}{|c|c|c|c|c|}
\hline & $\begin{array}{c}\text { Same- } \\
\text { Industry } \\
\text { (4-digit) }\end{array}$ & $\begin{array}{l}\text { Cross- } \\
\text { Industry }\end{array}$ & $\begin{array}{c}\text { Same- } \\
\text { Industry } \\
\text { (3-digit) }\end{array}$ & $\begin{array}{l}\text { Cross- } \\
\text { Industry }\end{array}$ \\
\hline \multicolumn{5}{|c|}{$\mathbf{I R}^{\mathrm{IM}}$} \\
\hline Mean $(\%)$ & 12.65 & 13.16 & 12.29 & 13.33 \\
\hline Median (\%) & 12.77 & 11.88 & 12.47 & 12.14 \\
\hline Sample size & 31 & 109 & 38 & 102 \\
\hline \multicolumn{5}{|c|}{ CIBR } \\
\hline Mean $(\%)$ & 11.01 & 8.51 & $11.66^{*}$ & $8.10^{*}$ \\
\hline Median (\%) & 12.13 & 7.28 & $11.81 * *$ & $6.98 * *$ \\
\hline Sample size & 31 & 110 & 38 & 103 \\
\hline \multicolumn{5}{|c|}{$\mathbf{I R}^{\mathrm{PSM}}$} \\
\hline Mean (\%) & 19.13 & 13.52 & $20.16 * *$ & $12.76^{* *}$ \\
\hline Median (\%) & $14.17 *$ & $8.96^{*}$ & $16.46 * *$ & $8.33 * *$ \\
\hline Sample size & 31 & 110 & 38 & 103 \\
\hline \multicolumn{5}{|c|}{ IR $^{\text {PSM }}$ - IR IR $_{\text {(Estimated Revelation Bias) }}$} \\
\hline Mean $(\%)$ & $6.48 *$ & $0.39 *$ & $7.87 * * *$ & $-0.55 * * *$ \\
\hline t-statistic & 1.91 & 0.25 & 2.63 & -0.35 \\
\hline Median (\%) & $5.72 *$ & $-0.02 *$ & $6.52 * * *$ & $-1.17 * * *$ \\
\hline Binomial p & 0.15 & 1.00 & 0.07 & 0.77 \\
\hline Sample size & 31 & 109 & 38 & 102 \\
\hline \multicolumn{5}{|c|}{ Bidder CAR } \\
\hline Mean (\%) & 1.25 & -0.50 & $2.01 *$ & $-0.90 *$ \\
\hline Median (\%) & $1.53 *$ & $-0.95^{*}$ & $1.74 * *$ & $-0.99 * *$ \\
\hline Sample size & 31 & 112 & 38 & 105 \\
\hline \multicolumn{5}{|c|}{ Target CAR } \\
\hline Mean (\%) & 29.55 & 29.95 & 30.39 & 29.67 \\
\hline Median (\%) & 30.91 & 25.85 & 30.22 & 24.67 \\
\hline Sample size & 31 & 113 & 38 & 106 \\
\hline
\end{tabular}

The mean Estimated Revelation Bias ( $\mathrm{IR}^{\mathrm{PSM}}-\mathrm{IR}^{\mathrm{IM}}$ ) may not equal the difference in means between the $\mathrm{IR}^{\mathrm{PSM}}$ and $I^{I M}$ entries owing to different sample size for $I^{P S M}$ and $I R^{I M}$. The median of $I^{P S M}-I^{I M}$ generally does not equal the difference in medians between the $\mathrm{IR}^{\mathrm{PSM}}$ and $\mathrm{IR}^{\mathrm{IM}}$ entries.

$t$-statistic is the Student's $t$ value that tests whether the mean is different from zero.

Binomial $p$ is the significance level for the two-tail Fisher sign test that tests whether the median revelation bias is different from zero.

$*, * *, * * *$ indicate significant difference between same- and cross-industry tender offers at the $10 \%, 5 \%, 1 \%$ levels, respectively. 
Table 7

The relation between value improvements and relative size

Implicit market estimates of the value improvement as a result of the takeover $\left(\mathrm{IR}^{\mathrm{IM}}\right)$, combined initial bid returns (CIBR), and probability-adjusted combined initial bid returns $\left(\mathrm{IR}^{\mathrm{PSM}}\right)$ over various relative size of bidder to target. These value improvement estimates are defined in the legend of Table 4, Panel A. Sample includes 1018 tender offers where both bidder and target were listed on the NYSE, AMEX, or NASDAQ during 1962-2001; additionally, for $\mathrm{IR}^{\mathrm{IM}}$ the sample is restricted to cases where there was a competing bid for the target.

Panel A: Sample includes 1018 tender offers where both bidder and target were listed on the NYSE, AMEX, or NASDAQ during 1962-2001.

\begin{tabular}{|l|c|c|c|c|}
\hline & \multicolumn{5}{|c|}{ Ratio of bidder-size to target-size } \\
\hline & $<\mathbf{0 . 7}$ & $\mathbf{0 . 7}-\mathbf{1 . 5}$ & $\mathbf{1 . 5}-\mathbf{5 . 0}$ & $>\mathbf{5}$ \\
\hline \multicolumn{5}{|c|}{ CIBR } \\
\hline Mean (\%) & 14.95 & 11.79 & 6.87 & 1.40 \\
\hline Median (\%) & 12.79 & 11.88 & 6.19 & 1.51 \\
\hline Sample size & 85 & 126 & 240 & 525 \\
\hline \multicolumn{5}{|c|}{ IR $^{\text {PSM }}$} \\
\hline Mean (\%) & 22.06 & 17.19 & 9.11 & 1.68 \\
\hline Median (\%) & 16.68 & 15.45 & 7.03 & 1.73 \\
\hline Sample size & 85 & 126 & 240 & 525 \\
\hline \multicolumn{5}{|c|}{ Bidder CAR } \\
\hline Mean (\%) & 3.75 & 2.26 & -1.16 & -0.47 \\
\hline Median (\%) & 1.74 & 1.81 & -1.53 & -0.41 \\
\hline Sample size & 85 & 127 & 240 & 526 \\
\hline \multicolumn{5}{|c|}{ Target CAR } \\
\hline Mean (\%) & 18.96 & 21.92 & 29.21 & 34.59 \\
\hline Median (\%) & 16.92 & 20.02 & 25.11 & 30.22 \\
\hline Sample size & 85 & 126 & 241 & 527 \\
\hline
\end{tabular}

Panel B: Sub-sample includes tender offers where there was a competing bid for the target.

\begin{tabular}{|c|c|c|c|c|}
\hline & \multicolumn{4}{|c|}{ Ratio of bidder-size to target-size } \\
\hline & $<0.7$ & $0.7-1.5$ & $1.5-5.0$ & $>5$ \\
\hline \multicolumn{5}{|c|}{$\mathbf{I R}^{\mathrm{IM}}$} \\
\hline Mean $(\%)$ & 25.87 & 16.74 & 9.71 & 5.93 \\
\hline Median (\%) & 26.73 & 16.75 & 9.64 & 5.39 \\
\hline Sample size & 22 & 31 & 61 & 27 \\
\hline \multicolumn{5}{|c|}{ CIBR } \\
\hline Mean $(\%)$ & 16.77 & 12.01 & 7.69 & 2.13 \\
\hline Median (\%) & 19.08 & 11.61 & 6.29 & 2.12 \\
\hline Sample size & 22 & 32 & 61 & 27 \\
\hline \multicolumn{5}{|c|}{ IR $^{\text {PSM }}$} \\
\hline Mean (\%) & 27.51 & 20.10 & 12.16 & 3.60 \\
\hline Median (\%) & 26.40 & 14.83 & 8.14 & 3.40 \\
\hline Sample size & 22 & 32 & 61 & 27 \\
\hline \multicolumn{5}{|c|}{ Bidder CAR } \\
\hline Mean (\%) & 1.22 & 0.97 & -1.34 & -0.50 \\
\hline Median (\%) & -0.10 & -0.25 & -2.08 & 0.05 \\
\hline Sample size & 22 & 32 & 61 & 27 \\
\hline \multicolumn{5}{|c|}{ Target CAR } \\
\hline Mean (\%) & 22.25 & 23.30 & 32.36 & 38.65 \\
\hline Median (\%) & 23.82 & 21.36 & 30.09 & 30.62 \\
\hline Sample size & 22 & 32 & 61 & 27 \\
\hline
\end{tabular}


Table 8

Determinants of returns and value improvements

Least squares regression results of combined initial bid returns (CIBR), and probability-adjusted combined initial bid returns $\left(\mathrm{IR}^{\mathrm{PSM}}\right)$, bidder and target abnormal returns against various takeover-specific variables. Sample includes tender offers where both bidder and target were listed on the NYSE, AMEX, or NASDAQ during 1962-2001 (tstatistics in parentheses.) Sample includes tender offers where bidder and target Tobin's Q and leverage ratios are available. Industries are classified according to 3-digit COMPUSTAT SIC codes.

\begin{tabular}{|c|c|c|c|c|c|c|}
\hline \multirow[b]{2}{*}{ Independent Variable } & \multicolumn{6}{|c|}{ Dependent Variable } \\
\hline & CIBR & IR $^{\text {PSM }}$ & CIBR & IR $^{\text {PSM }}$ & $\begin{array}{c}\text { Bidder } \\
\text { CAR }\end{array}$ & $\begin{array}{c}\text { Target } \\
\text { CAR }\end{array}$ \\
\hline Hostile & $\begin{array}{c}0.50 \\
(0.63) \\
\end{array}$ & $\begin{array}{r}6.93 \\
(6.62) \\
\end{array}$ & $\begin{array}{c}1.05 \\
(1.12) \\
\end{array}$ & $\begin{array}{c}7.63 \\
(6.00) \\
\end{array}$ & $\begin{array}{c}-1.63 \\
(-1.83) \\
\end{array}$ & $\begin{array}{c}5.93 \\
(2.46) \\
\end{array}$ \\
\hline Cash & $\begin{array}{c}2.31 \\
(2.97) \\
\end{array}$ & $\begin{array}{c}3.17 \\
(3.12) \\
\end{array}$ & $\begin{array}{c}2.69 \\
(3.05) \\
\end{array}$ & $\begin{array}{c}3.86 \\
(3.22) \\
\end{array}$ & $\begin{array}{c}2.28 \\
(2.71) \\
\end{array}$ & $\begin{array}{c}2.77 \\
(1.22) \\
\end{array}$ \\
\hline Stock & $\begin{array}{c}-5.12 \\
(-3.14)\end{array}$ & $\begin{array}{c}-6.34 \\
(-2.96)\end{array}$ & $\begin{array}{c}-4.81 \\
(-2.20) \\
\end{array}$ & $\begin{array}{c}-5.20 \\
(-1.76)\end{array}$ & $\begin{array}{c}-2.41 \\
(-1.16)\end{array}$ & $\begin{array}{l}-16.05 \\
(-2.86) \\
\end{array}$ \\
\hline Pre-Williams Act & $\begin{array}{c}1.00 \\
(0.76) \\
\end{array}$ & $\begin{array}{c}1.55 \\
(0.89) \\
\end{array}$ & $\begin{array}{c}2.98 \\
(0.84) \\
\end{array}$ & $\begin{array}{c}7.18 \\
(1.49) \\
\end{array}$ & $\begin{array}{c}4.54 \\
(1.34) \\
\end{array}$ & $\begin{array}{c}-1.04 \\
(-0.11) \\
\end{array}$ \\
\hline Post-March 2000 & $\begin{array}{c}2.74 \\
(2.37) \\
\end{array}$ & $\begin{array}{c}3.24 \\
(2.14) \\
\end{array}$ & $\begin{array}{c}2.31 \\
(1.72) \\
\end{array}$ & $\begin{array}{c}2.48 \\
(1.36) \\
\end{array}$ & $\begin{array}{c}-0.05 \\
(-0.04) \\
\end{array}$ & $\begin{array}{l}11.22 \\
(3.24) \\
\end{array}$ \\
\hline Same Industry & $\begin{array}{c}1.60 \\
(2.42) \\
\end{array}$ & $\begin{array}{c}1.85 \\
(2.13) \\
\end{array}$ & $\begin{array}{c}1.37 \\
(1.78) \\
\end{array}$ & $\begin{array}{c}1.47 \\
(1.42) \\
\end{array}$ & $\begin{array}{c}2.11 \\
(2.89) \\
\end{array}$ & $\begin{array}{c}0.79 \\
(0.40) \\
\end{array}$ \\
\hline Log of Relative Size & $\begin{array}{c}-2.74 \\
(-14.51)\end{array}$ & $\begin{array}{c}-3.35 \\
(-13.53)\end{array}$ & $\begin{array}{c}-2.53 \\
(-11.14)\end{array}$ & $\begin{array}{c}-3.10 \\
(-10.06)\end{array}$ & $\begin{array}{c}-0.36 \\
(-1.69) \\
\end{array}$ & $\begin{array}{c}3.58 \\
(6.13) \\
\end{array}$ \\
\hline Log of Target Size & $\begin{array}{c}-0.69 \\
(-3.05) \\
\end{array}$ & $\begin{array}{c}-0.65 \\
(-2.21) \\
\end{array}$ & $\begin{array}{c}-0.65 \\
(-2.41) \\
\end{array}$ & $\begin{array}{c}-0.50 \\
(-1.38) \\
\end{array}$ & $\begin{array}{c}-0.61 \\
(-2.40) \\
\end{array}$ & $\begin{array}{c}-1.16 \\
(-1.69) \\
\end{array}$ \\
\hline Bidder Tobin's Q & & & $\begin{array}{c}-0.28 \\
(-2.66) \\
\end{array}$ & $\begin{array}{c}-0.39 \\
(-2.73) \\
\end{array}$ & $\begin{array}{c}-0.38 \\
(-3.72) \\
\end{array}$ & $\begin{array}{c}-0.16 \\
(-0.57) \\
\end{array}$ \\
\hline Target Tobin's Q & & & $\begin{array}{c}0.12 \\
(0.74)\end{array}$ & $\begin{array}{c}0.14 \\
(0.62) \\
\end{array}$ & $\begin{array}{c}0.13 \\
(0.83) \\
\end{array}$ & $\begin{array}{c}-0.97 \\
(-2.26) \\
\end{array}$ \\
\hline Constant & $\begin{array}{l}11.78 \\
(7.27) \\
\end{array}$ & $\begin{array}{l}12.61 \\
(5.93) \\
\end{array}$ & $\begin{array}{l}11.64 \\
(6.13) \\
\end{array}$ & $\begin{array}{l}11.93 \\
(4.63) \\
\end{array}$ & $\begin{array}{c}2.71 \\
(1.50) \\
\end{array}$ & $\begin{array}{l}28.47 \\
(5.84) \\
\end{array}$ \\
\hline Sample Size & 935 & 935 & 634 & 634 & 636 & 635 \\
\hline Adjusted R ${ }^{2}$ & .2206 & .2699 & .2242 & .2751 & .0530 & .1147 \\
\hline
\end{tabular}

Hostile $=1$ if the offer is viewed as hostile by target management; 0 otherwise.

Cash $=1$ if the offer is all cash; 0 otherwise.

Stock $=1$ if the offer is all stock; 0 otherwise.

Pre-Williams Act $=1$ if the offer was made prior to July 1968; 0 otherwise.

Post-March $2000=1$ if the offer was made after March 2000; 0 otherwise.

Same Industry $=1$ if the bidder and target are in the same 3-digit COMPUSTAT SIC code industry; 0 otherwise.

Relative Size =acquirer market value $/$ target market value.

Tobin's Q = (market value of equity + long-term debt + short-term debt + preferred stock)/ total assets.

The value improvement estimates CIBR and IR $^{\text {PSM }}$ are defined in the legend of Table 4, Panel A. 
Table 9

The difference between value improvement measures and toehold-adjusted bid premium

Value improvement measures include the implicit market estimates of the value improvement as a result of the takeover $\left(\mathrm{IR}^{\mathrm{IM}}\right.$ ), combined initial bid returns (CIBR), and probability-adjusted combined initial bid returns (IR ${ }^{\mathrm{PSM}}$ ). These value improvement estimates are defined in the legend of Table 4, Panel A. Sample includes tender offers where both bidder and target were listed on the NYSE, AMEX, or NASDAQ during 1962-2001; additionally, for $\mathrm{IR}^{\mathrm{IM}}$ the sample is restricted to cases where there was a competing bid for the target. All improvement ratios are expressed as a $\%$ of combined target and bidder market value.

\begin{tabular}{|c|c|c|c|c|c|c|c|c|c|}
\hline & \multicolumn{8}{|c|}{ Sub-period } & \multirow{2}{*}{$\begin{array}{l}\text { Total } \\
7 / 62- \\
12 / 01 \\
\end{array}$} \\
\hline & $\begin{array}{l}7 / 62- \\
6 / 68 \\
\end{array}$ & $\begin{array}{l}7 / 68- \\
12 / 80 \\
\end{array}$ & $\begin{array}{l}1 / 81- \\
12 / 84\end{array}$ & $\begin{array}{l}1 / 85- \\
12 / 88 \\
\end{array}$ & $\begin{array}{l}1 / 89- \\
12 / 92 \\
\end{array}$ & $\begin{array}{l}1 / 93- \\
12 / 96 \\
\end{array}$ & $\begin{array}{c}1 / 97- \\
3 / 00 \\
\end{array}$ & $\begin{array}{l}4 / 00- \\
12 / 01 \\
\end{array}$ & \\
\hline \multicolumn{10}{|c|}{ CIBR - ToePrem (full sample) } \\
\hline Mean $(\%)$ & -0.11 & -4.41 & -2.34 & -4.26 & -3.53 & -1.05 & -1.53 & -1.96 & -2.66 \\
\hline Median (\%) & 0.35 & -2.33 & -4.73 & -3.13 & -2.61 & 0.57 & -1.62 & -0.84 & -1.93 \\
\hline$\%$ positive & 54.2 & 34.5 & 27.3 & 31.8 & 30.9 & 54.7 & 42.2 & 47.3 & 40.0 \\
\hline p-value of mean & 0.91 & 0.00 & 0.31 & 0.00 & 0.00 & 0.21 & 0.02 & 0.20 & 0.00 \\
\hline Binomial p & 0.60 & 0.00 & 0.00 & 0.00 & 0.00 & 0.31 & 0.03 & 0.73 & 0.00 \\
\hline Sample size & 59 & 145 & 44 & 211 & 81 & 137 & 204 & 74 & 955 \\
\hline \multicolumn{10}{|c|}{ IR $^{\text {PSM }}$ - ToePrem (full sample) } \\
\hline Mean $(\%)$ & 3.70 & -1.71 & 2.77 & -1.62 & -2.04 & 0.29 & -0.33 & -1.70 & -0.59 \\
\hline Median (\%) & 3.46 & -0.23 & -1.82 & -1.59 & -1.04 & 1.19 & -0.93 & -0.78 & -0.48 \\
\hline$\%$ positive & 64.4 & 49.0 & 45.5 & 42.2 & 39.5 & 58.4 & 45.6 & 47.3 & 48.0 \\
\hline p-value of mean & 0.02 & 0.17 & 0.32 & 0.07 & 0.06 & 0.74 & 0.67 & 0.28 & 0.14 \\
\hline Binomial $\mathrm{p}$ & 0.04 & 0.87 & 0.65 & 0.03 & 0.07 & 0.06 & 0.23 & 0.73 & 0.22 \\
\hline Sample size & 59 & 145 & 44 & 211 & 81 & 137 & 204 & 74 & 955 \\
\hline \multicolumn{10}{|c|}{ IR $^{\mathrm{IM}}$ - ToePrem (competing bid sub-sample) } \\
\hline Mean $(\%)$ & 5.46 & 0.03 & -2.47 & -7.27 & 3.86 & -0.90 & -3.38 & 7.79 & -1.45 \\
\hline Median (\%) & 6.42 & 1.67 & -7.09 & -3.82 & 2.32 & 3.14 & -2.07 & 6.64 & -0.07 \\
\hline$\%$ positive & 82.4 & 58.1 & 16.7 & 29.7 & 66.7 & 54.5 & 42.9 & 100.0 & 49.6 \\
\hline p-value of mean & 0.00 & 0.99 & 0.76 & 0.02 & 0.21 & 0.84 & 0.30 & 0.08 & 0.27 \\
\hline Binomial $\mathrm{p}$ & 0.01 & 0.47 & 0.04 & 0.02 & 0.51 & 1.00 & 0.79 & 0.13 & 1.00 \\
\hline Sample size & 17 & 31 & 12 & 37 & 9 & 11 & 14 & 4 & 135 \\
\hline \multicolumn{10}{|c|}{ CIBR - ToePrem (competing bid sub-sample) } \\
\hline Mean $(\%)$ & -1.15 & -3.51 & 0.83 & -10.48 & -2.67 & -8.32 & -4.03 & -1.26 & -5.06 \\
\hline Median (\%) & -0.62 & -1.74 & -7.04 & -5.74 & -1.64 & -5.60 & -3.14 & 4.47 & -2.95 \\
\hline$\%$ positive & 47.1 & 35.5 & 33.3 & 27.0 & 33.3 & 36.4 & 42.9 & 50.0 & 35.6 \\
\hline p-value of mean & 0.67 & 0.04 & 0.92 & 0.00 & 0.26 & 0.12 & 0.19 & 0.89 & 0.00 \\
\hline Binomial $\mathrm{p}$ & 1.00 & 0.15 & 0.39 & 0.01 & 0.51 & 0.55 & 0.79 & 1.00 & 0.00 \\
\hline Sample size & 17 & 31 & 12 & 37 & 9 & 11 & 14 & 4 & 135 \\
\hline \multicolumn{10}{|c|}{ IR $^{\text {PSM }}$ - ToePrem (competing bid sub-sample) } \\
\hline Mean (\%) & 3.41 & -0.25 & 14.78 & -2.17 & 2.33 & -7.55 & 2.73 & -0.10 & 0.91 \\
\hline Median (\%) & 3.34 & 0.37 & 6.50 & -1.13 & -0.48 & -5.24 & 2.98 & 5.06 & 0.56 \\
\hline$\%$ positive & 58.8 & 54.8 & 75.0 & 48.6 & 44.4 & 45.5 & 57.1 & 50.0 & 54.1 \\
\hline p-value of mean & 0.37 & 0.90 & 0.09 & 0.52 & 0.63 & 0.17 & 0.50 & 0.99 & 0.56 \\
\hline Binomial $\mathrm{p}$ & 0.63 & 0.72 & 0.15 & 1.00 & 1.00 & 1.00 & 0.79 & 1.00 & 0.39 \\
\hline Sample size & 17 & 31 & 12 & 37 & 9 & 11 & 14 & 4 & 135 \\
\hline
\end{tabular}

$p$-value of mean is the significance level for the Student's $t$ value that tests whether the mean is different from zero. Binomial $p$ is the significance level for the two-tail Fisher sign test that tests whether the median is different from zero. The difference between value improvement and toehold-adjusted bid premium (ToePrem) is equal to the difference between the RHS and the LHS of equation (2) in the text.

ToePrem $=(1$-alpha $) *($ bid premium $) *$ Target market value/Combined bidder and target market value, where alpha is the fraction of pre-bid target shares held by the bidder. 
Table 10

Sensitivity of $\mathrm{IR}^{\mathrm{IM}}$ to alternative modeling specifications

This table provides a sensitivity analysis for $\mathrm{IR}^{\mathrm{IM}}$, the value improvement as a result of the takeover, with respect to parameter values in several variations of the basic model. Columns 1 and 2 describe the effects

of varying $K$, the ratio of the expected post-takeover value of the target to the first bidder conditional on a competing bid arriving to the unconditional expected value. Columns 3 and 4 vary $\gamma$, the probability that after failure the first bidder will seek and acquire an identical target. Columns 5-7 vary $\operatorname{Pr}\left(\mathrm{S}^{2} \mid \theta_{3}\right)$, the probability that a second bidder wins given that he enters the contest, in order to allow for the benefits derived by a defeated first bidder from selling his initial shareholding to a competing bidder. Column 6 is based on the actual first bidder initial shareholding, and Column 7 is based on an initial shareholding of 0.15 . Parameter inputs for computation of $\mathrm{IR}^{\mathrm{IM}}$ are derived from regression/logit models A1 and B (see Table 3).

\begin{tabular}{|c|c|c|c|c|c|c|}
\hline $\boldsymbol{K}$ & $\begin{array}{c}\mathbf{I R}^{\mathbf{I M}} \mathbf{( \% )} \\
\text { mean/median }\end{array}$ & $\gamma$ & $\begin{array}{c}\mathbf{I R}^{\mathbf{I M}} \mathbf{( \% )} \\
\text { mean/median }\end{array}$ & $\mathbf{P r}\left(\mathbf{S}^{\mathbf{2}} \mid \boldsymbol{\theta}_{3}\right)$ & $\begin{array}{c}\mathbf{I R}^{\mathbf{I M}} \mathbf{( \% )} \\
\text { Mean/median }\end{array}$ & $\begin{array}{c}\mathbf{I R}^{\mathbf{I M}} \mathbf{( \% )} \\
\text { mean/median }\end{array}$ \\
\hline 1.00 & $14.8 / 13.8$ & 0.0 & $14.8 / 13.8$ & 0.0 & $14.8 / 13.8$ & $13.2 / 12.1$ \\
\hline 1.10 & $15.8 / 15.2$ & 0.2 & $14.5 / 13.5$ & 0.1 & $14.9 / 13.8$ & $14.1 / 12.7$ \\
\hline 1.20 & $17.5 / 16.9$ & 0.4 & $14.3 / 14.1$ & 0.3 & $15.3 / 14.2$ & $15.7 / 14.1$ \\
\hline 1.30 & $18.4 / 19.0$ & 0.6 & $14.0 / 14.6$ & 0.5 & $15.6 / 14.3$ & $17.1 / 16.0$ \\
\hline 1.40 & $19.0 / 20.8$ & 1.0 & $13.4 / 14.3$ & 0.7 & $15.9 / 14.8$ & $18.5 / 18.2$ \\
\hline
\end{tabular}

